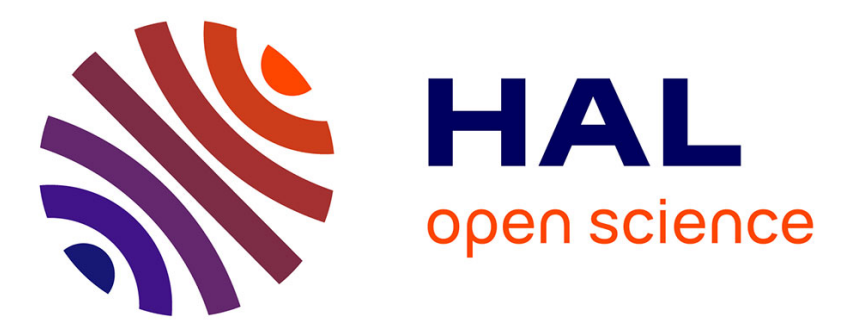

\title{
Experimental Study of Pyrolysis-Combustion Coupling in a Regeneratively Cooled Combustor: System Dynamics Analysis
}

Taddeo Lucio, Nicolas Gascoin, Khaled Chetehouna, Antonella Ingenito, Fulvio Stella, Marc Bouchez, Bruno Le Naour

\section{To cite this version:}

Taddeo Lucio, Nicolas Gascoin, Khaled Chetehouna, Antonella Ingenito, Fulvio Stella, et al.. Experimental Study of Pyrolysis-Combustion Coupling in a Regeneratively Cooled Combustor: System Dynamics Analysis. Aerospace Science and Technology, 2017, 10.1016/j.ast.2017.04.026 . hal-01570491

\section{HAL Id: hal-01570491 \\ https://hal.science/hal-01570491}

Submitted on 30 Jul 2017

HAL is a multi-disciplinary open access archive for the deposit and dissemination of scientific research documents, whether they are published or not. The documents may come from teaching and research institutions in France or abroad, or from public or private research centers.
L'archive ouverte pluridisciplinaire HAL, est destinée au dépôt et à la diffusion de documents scientifiques de niveau recherche, publiés ou non, émanant des établissements d'enseignement et de recherche français ou étrangers, des laboratoires publics ou privés. 


\section{Experimental study of pyrolysis-combustion coupling in a regeneratively cooled combustor: System dynamics analysis}

Article in Aerospace Science and Technology · May 2017

DOI: 10.1016/j.ast.2017.04.026

CITATIONS

0

7 authors, including:

Nicolas Gascoin

Institut National des Sciences Appliquées Ce... 107 PUBLICATIONS 489 CITATIONS

SEE PROFILE

\section{Antonella Ingenito}

Sapienza University of Rome

60 PUBLICATIONS 279 CITATIONS

SEE PROFILE
READS

18
Khaled Chetehouna

Institut National des Sciences Appliquées Ce...

37 PUBLICATIONS 48 CITATIONS

SEE PROFILE

\section{Marc Bouchez}

MBDA France

85 PUBLICATIONS 613 CITATIONS

SEE PROFILE

Some of the authors of this publication are also working on these related projects: 


\title{
Experimental Study of Pyrolysis-Combustion Coupling in a Regeneratively Cooled Combustor: System Dynamics Analysis
}

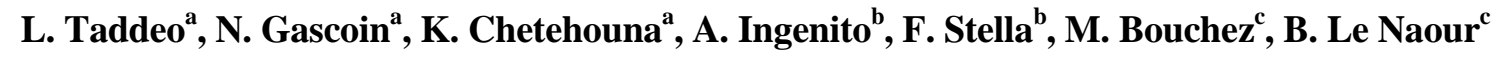 \\ ${ }^{a}$ INSA Centre Val de Loire, 88 boulevard Lahitolle, Bourges, France \\ bUniversity of Rome “La Sapienza”, Department of Mechanics and Aeronautics, 18 via \\ Eudossiana, Rome, Italy

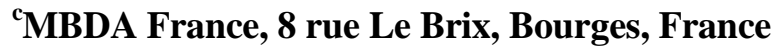

\begin{abstract}
Scramjets are suitable for hypersonic flight, but their use requires the ability to ensure their thermal protection. In this context, a remotely controlled fuel-cooled combustor, suitable for the experimental analysis of the pyrolysis-combustion coupling characterizing a regeneratively cooled combustion chamber when a hydrocarbon propellant is used, has been designed. Similitude rules were used. Ethylene is used as fuel, air as oxidizer, with an equivalence ratio between 1.0 and 1.5 and a fuel injection pressure between 1 and 10 bar. Experiments are realized by varying operating conditions, to determine their impact on combustor heat transfer dynamics. Previous numerical results have been confirmed. A hysteresis effect has been demonstrated. It has been observed that system response time to fuel mass flow rate increases is lower (of about 40 to $50 \%$ ) than system response time to fuel mass flow rate decreases and that a rise in equivalence ratio from 1.0 to 1.25 produces an increase in system response intensity that is, following the operating conditions, in the range from $90 \%$ to $170 \%$. It has also been seen that an increase in equivalence ratio from 1.0 to 1.5 produces a raise of the temperature of the fuel-coolant (of about 40 to $50 \%$ ), due to the increase in the emissivity of the flame.
\end{abstract}

\section{Keywords}

\section{Scramjet}

Hydrocarbon Fuel Pyrolysis

Corresponding Author: Lucio Taddeo, 26 rue Moyenne, Bourges, France (lucio.taddeo@insa-cvl.fr) 
Combustion-Pyrolysis Coupling

Regenerative Cooling

Parametrical Analysis

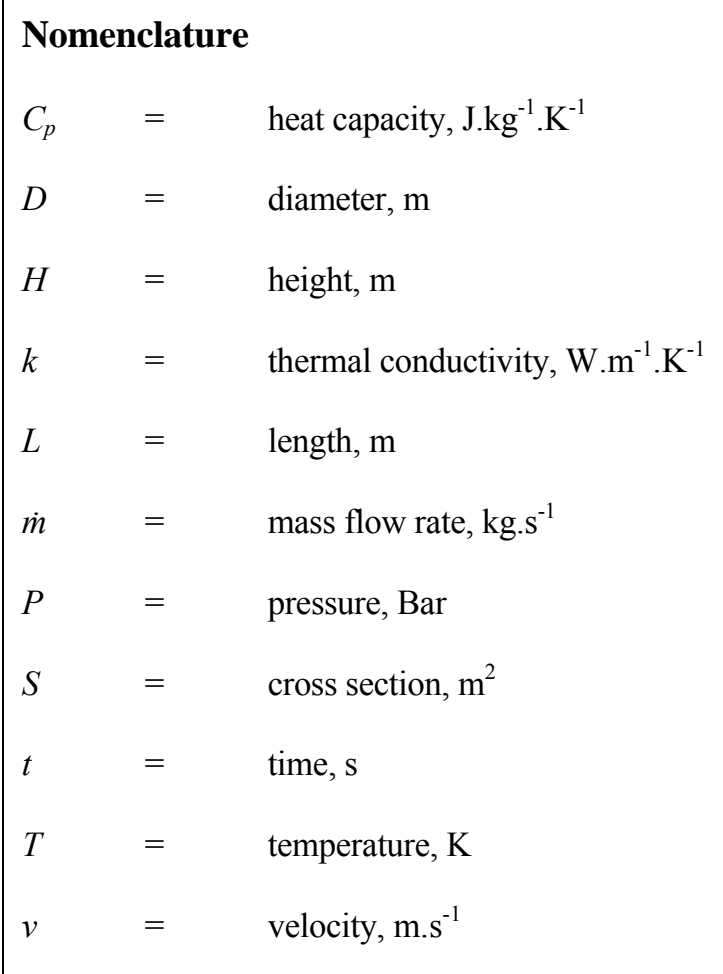

\section{Greek Symbols}

$\varepsilon \quad=\quad$ emissivity, dimensionless

$\varphi \quad=\quad$ equivalence ratio of fuel to oxidizer, dimensionless

$\mu \quad=\quad$ dynamic viscosity, Pa.s

$\rho \quad=\quad$ density, $\mathrm{kg} \cdot \mathrm{m}^{-3}$

$\sigma \quad=\quad$ Boltzmann's constant, W. $\mathrm{m}^{-2} \cdot \mathrm{K}^{-4}$

\section{Subscripts}

$$
\begin{array}{lll}
\mathrm{cc} & = & \text { cooling channel } \\
\mathrm{f} & = & \text { fuel fed to the cooling channel } \\
\mathrm{g} & = & \text { combustion gases } \\
\mathrm{g}, \mathrm{th} & = & \text { combustion gases in the vicinity of the thermocouple } \\
\mathrm{hf} & = & \text { fuel at cooling channel outlet, before injection in the burner }
\end{array}
$$




\section{Introduction}

For decades, hypersonic flight has challenged researchers. Indeed, both reusable aircrafts and space vehicles able to reach velocities over Mach 5 may provide significant commercial benefits. Hypersonic flight is also suitable for military applications, as the development of hypersonic missiles [1]. Because of the operational limitation of gas turbine engines to speeds generally below Mach 4, the propulsion systems for high-speed flight must integrate engines capable of propelling the vehicle when its velocity becomes hypersonic. To this end, Scramjets, which are air-breathing jet engines suitable for atmospheric flight, represent a very effective solution [2-4].

Yet, when flight velocities increase beyond supersonic speeds, the difficulties accompanying aircraft design grow, particularly with respect to vehicle thermal protection, which becomes a critical problem notably with regard to the engine combustion chamber, exposed to very high temperatures, higher of all known structural materials capability [5-8]. The combustor wall must also face a very high heat load (at Mach 8 the average heat flux passing from the combustion gases to the combustor wall has been estimated to be about 1.7 MW. ${ }^{-2}$ ) [9]. Furthermore, the heat flux distribution characterizing Scramjet engines can result in hot spots where heat flux is expected to exceed 5.7 MW.m ${ }^{-2}$ [7].

Several cooling techniques can be used to protect the combustor internal surfaces, in order to maintain its structures at a limited and safe temperature. In general, they are divided into passive ones, where no coolant is used, and active ones, where a coolant is used $[10,11]$. Active cooling techniques consist in the injection of a coolant through cooling channels located in the combustion chamber wall. As at hypersonic speeds air stagnation temperature is too high to use incoming air as an effective coolant, the fuel becomes the primary cooling source, providing both coolant capability for heat removal and heat sink capacity for storing the absorbed heat $[7,12]$. In this sense, endothermic hydrocarbon jet fuels represent very attractive coolants. Their heat sink potential is both a sensible one, through fuel heating (in the order of 1-1.5 $\mathrm{kJ}^{\mathrm{kg}} \mathrm{kg}^{-1}$ ), and a chemical one, through decomposition heat-absorbing reactions that can occur when the fuel is heated at temperatures over $750 \mathrm{~K}$ (in the order of $\left.1.5-3.5 \mathrm{~kJ} . \mathrm{kg}^{-1}\right)[7,13]$. 
One of the most common active cooling technique using the fuel as coolant is regenerative cooling. The fuel flows through cooling channels located between the inner and the outer walls of the engine, before being injected in the combustor; a counter-flow heat exchange between the fuel-coolant and the burned gases is thus established $[5,14]$. Regenerative cooling is particularly effective when an endothermic propellant is used as fuelcoolant as fuel decomposition in the cooling channels also generates light species, mainly hydrogen, ethane, ethylene, acetylene, whose ignition delay times are very low when compared to the initial heavy propellant. Thus, fuel combustion kinetics becomes faster and the performance of the engine improves [13-15].

The design of a regeneratively cooled engine is very challenging, as the definition of an engine regulation strategy allowing to master the various conditions encountered during the flight requires the ability to manage several issues [13-17]. First, the design of the combustion chamber and of the cooling channels. Second, the evaluation of the heat fluxes passing from the combustion gases to the combustor internal walls and of the highest heat flux regions. Third, the choice of the materials that are more suitable for combustor structures. Forth, the understanding of the complex pyrolysis reactions characterizing fuel decomposition and of the coupling between fuel pyrolysis and fuel combustion (which affect each other). Finally, when the engine is fueled with hydrocarbons, the comprehension of the possible consequences on the heat transfer efficiency of the cooling system of the coking activity typical of hydrocarbons thermal decomposition.

These issues have been studied in the framework of various programs [4-6,7-14,17,2242]. Many numerical studies, directed at estimating the heat flux density passing from the combustion gases to the combustor wall, the highest heat flux combustor regions and the heat flux absorbed by the pyrolyzing fuel are available [4-6,9,10,12-14]. The design of the regeneratively cooled combustion chambers, the definition of the shape of the cooling channels and the choice of materials appropriate for endothermic fuel cooled structures have been investigated, mainly by means of numerical calculations, since the 1990s [5,22-26]. Numerical investigations have also been performed to determine the effect of the shape and of the number of the cooling channels on combustion chamber walls, coolant temperature and fuel-coolant pressure drop [5,24]. The physical properties of composite materials suitable for the manufacturing of the combustor and of the cooling channels walls have been thoroughly studied [17,27-30]. The possibility of employing carbon composite materials instead of steel and copper alloys has been investigated [28-30]. 
Studies have also been performed on hydrocarbons thermal pyrolysis [31-35]. Within the framework of the PROMETHEE project, experiments on hydrocarbon jet-fuels pyrolysis have been run, to identify the main products of hydrocarbons decomposition under supercritical conditions (fuel pressure up to $80 \mathrm{bar}$ and fuel temperature up to $1200 \mathrm{~K}$ ). The main cracking products have been identified for various operating conditions of pressure, temperature and residence time [31]. In this context, it is worth mentioning the studies of Daniau and Sicard [32] and Vincent-Randonnier et al. [33], who showed that fuel pyrolysis in a regeneratively cooled engine is normally a kinetically controlled process. The COMPARER project, developed by the University of Orleans and by MBDA-France, aimed at identifying methods suitable to measure some of the most important parameters characterizing hydrocarbon-fueled regeneratively cooled engines, such as fuel mass flow rate and fuel composition at combustor inlet. Within its framework, it is important to evoke the studies of Abraham et al. [34] and Gascoin et al. [35].

Hydrocarbon fuels coking activity has also being deeply investigated [36-41]. Song et al. [36] and Chin and Lefebvre [37] studied the effects on jet fuels cooking activity of fuel and wall temperatures, fuel mass flow rate, velocity and pressure. They observed that fuel temperature and velocity are the most important factor affecting deposits formation. Sobel et al. [38] and Spadaccini et al. [39] investigated coke deposition in heated aircraft fuels by considering a wide temperature range, going from 420 to $820 \mathrm{~K}$, in order to analyze the contribution to carbon deposition of both thermal-oxidative and pyrolytic deposits. They found out that for a liquid fuel the variation of fuel pressure has a minor effect on coke formation. Maurice et al. [7] and Gascoin et al. [40] indicated that there is a residence time influence on pyrolytic deposition levels beyond the influence associated with conversion level. Finally, the analysis of the effect of the operating conditions of the cooling system, realized by considering the coupling among flow, heat transfer and chemical reactions in the cooling channels, has been carried out by Bao et al. [10].

However, to the author's knowledge, none of published studies focused on the most important aspect characterizing regeneratively cooled combustors, i.e. the strong coupling between fuel decomposition and fuel combustion, which makes the definition of an engine regulation strategy very hard. This is a very important point, as even the effect of the most important operating parameter, i.e. fuel mass flow rate, on engine thrust is not easy to determine. In fact, engine thrust depends both upon fuel mass flow rate and fuel composition, which are linked to each other, as fuel composition vary with fuel residence time in the 
cooling channels that, in turn, vary with fuel mass flow rate. A mass flow rate increase would probably result in a residence time decrease and, consequently, fuel decomposition could be less enhanced. Thus, the propellant injected in the combustor would contain less low ignition delay time species. The global effect could even be a drop in the engine thrust or even flame extinction $[13,14,43-45]$.

To the author's knowledge, the only work proceeding along this path is the one of Gascoin et al. [13], in which the impact of fuel mass flow rate on important parameters such as burned gases temperature and fuel-coolant temperature and residence time in the cooling channels has partially been defined by means of numerical calculations. This work has highlighted the complexity of the matter, showing the existence of hysteresis phenomena that make system control even more challenging. Now, the following tasks must be accomplished: 1) the already acquired numerical knowledge must be validated by means of experiments; 2) the characteristic times of all the involved physical and chemical phenomena, which are still unknown, must be determined and compared to those specific of engine control, to understand with which degree of effectiveness operating parameters variations can influence engine thrust; 3) the regeneratively cooled engine potential in terms of heat recovery and of utilization on long-live aircraft systems (more than 2000 hours) when a hydrocarbon fuel is used must be fully understood.

The objective of this study is to validate the numerically acquired knowledge and to understand the dynamics of a regeneratively cooled Scramjet fueled with an endothermic hydrocarbon, aiming at developing an engine control strategy suitable for a vahicle flying at hypersonic velocities. Thanks to an innovative experimental set-up, consisting of a lab-scale fuel-cooled combustor suitable for the experimental study of fuel combustion - fuel pyrolysis coupling, some of the most relevant issues characterizing this cooling technology have been experimentally investigated [14]. Experiments are run using ethylene as fuel-coolant and air as oxidizer. The effect of two operating parameters, i.e. fuel mass flow rate and fuel to oxidizer equivalence ratio, is analyzed.

The evaluation and the comprehension of the effects of fuel pyrolysis-fuel combustion and the identification of the most important system characteristic times are the main goals of this work. The effects of fuel mass flow rate and fuel to oxidizer equivalence ratio on the heat flux density passing from the combustion gases to the combustor wall, the sensible heat flux absorbed by the fuel-coolant, the heat loss due to the exhaust gases and the heat loss due to 
heat transfer from the combustor external surface to the surrounding environment and on the heat transfer efficiency of the combustor will be presented in a future work.

In the authors' opinion, this study will improve the knowledge of the scientific community on the thermal management and dynamic control of a Scramjet combustion chamber equipped with a regenerative cooling system.

\section{Materials and Methods}

\subsection{Description of the experimental set-up}

The bench used to run all the experiments consists in an automated combustion chamber which enables the study of the dynamics of a regenerative cooled engine. It allows the experimental investigation of the coupling between fuel pyrolysis and fuel combustion and of the coking activity of the fuel. The combustor, whose height is of $0.5 \mathrm{~m}$, is composed of two stainless steel co-axial tubes having respectively a diameter of $0.1 \mathrm{~m}$ (the internal one) and of $0.3 \mathrm{~m}$ (the external one) and a thickness of $1 \mathrm{~mm}$. An insulation blanket, made of a ceramic refractory, whose density is $128 \mathrm{~kg} \cdot \mathrm{m}^{-3}$ and whose thermal conductivity is $0.33 \mathrm{~W} \cdot \mathrm{m}^{-1} \cdot \mathrm{K}^{-1}$, is located between them. The cooling channels are reproduced by a single rolled-up stainless steel tube having a length of $40 \mathrm{~m}$, an internal diameter of $1 \mathrm{~mm}$ and a thickness of $1.1 \mathrm{~mm}$, which passes in the combustion chamber and is placed on the internal surface of its internal wall.

A scheme of the experimental set-up is given in fig. 1. The path followed by the fuel fed to the combustor, which is ethylene, is represented in blue. As shown in fig. 1, this hydrocarbon enters the rolled-up stainless steel cooling channel at position 1, at the top of the combustor. Then, it flows into this channel, absorbing part of the heat flux passing from the combustion gases to the internal surface of the combustion chamber wall. Thanks to this, its temperature raises reaching values that are sufficiently high to permit its thermal decomposition. As a result of this decomposition, fuel composition at position 2 (where the rolled-up cooling channel leaves the combustion chamber) is unknown. The mixture resulting from the pyrolysis of the ethylene originally fed to the combustor is finally injected in the burner.

The burner used to generate the flame is a Five North American SPB5 pilot burner, provided with a venturi jet mixer body which enables to mix the fuel and the oxidizer (which is air at ambient pressure) in order to produce a pre-mixed combustion, having a nominal 
capacity of $6 \mathrm{~kW}$. The choice of a premixed flame was made to facilitate the numerical study of the system, as a diffusion flame is much more complex to reproduce with CFD calculations. Before being injected in the burner, the fuel passes through a steel permeation cell (indicated as $P C$ in fig. 1), containing a stainless steel porous disk which can collect the particles of coke generated by the decomposition of the fuel and separate them as a function of their granulometry. Each disk has a diameter of $3 \mathrm{~cm}$ and a thickness of $3 \mathrm{~mm}$, presenting an overall porosity of $30 \%$; the average diameter of the pores is $4.1 \mu \mathrm{m}$ [46]. The properties of the coke that accumulates in permeation cell could be later analyzed by GC-MS analysis.

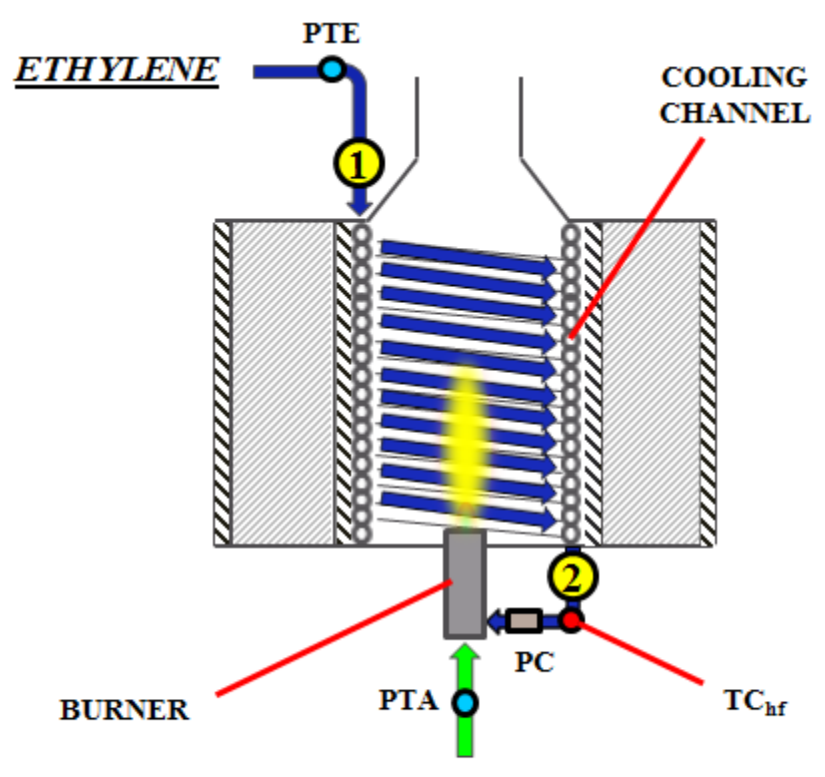

$\underline{A I R}$

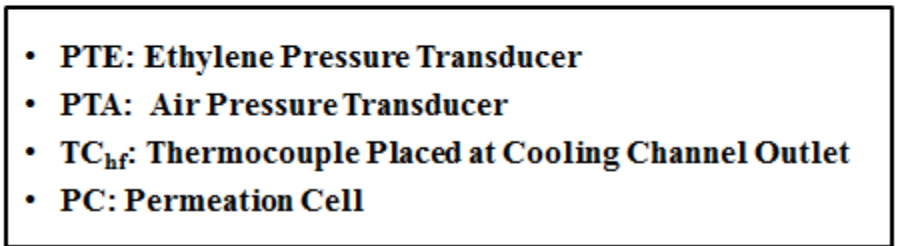

Figure 1. Scheme of the regeneratively cooled combustion chamber

The ethylene and the air that are used to carry out the tests are stocked at high pressure (above 100 bar) and are fed to the combustor by using two high-precision mass flow controllers, respectively a Bronkhorst F-201CM-10K-RDA-88-K for ethylene (with a range of 0-0.2 g.s ${ }^{-1}$ ) and a Bronkhorst F-202AV-M20-RDA-55-V for air (with a range of 0-5 g.s ${ }^{-1}$ ). A pressure transducer with a range between 0 and 100 bar (Baumer CTX155B115, indicated as PTE in fig. 1) and a pressure transducer with a range between 0 and 10 bar (Baumer CTX255B255, indicated as PTA in fig. 1) are used to measure respectively the pressure of the 
ethylene entering the cooling channel and of the air entering the burner. Temperatures in the combustion chamber are measured by chromel-alumel type $\mathrm{K}$ thermocouples, which can be shifted from the wall to the axis of the combustor. Their positions are shown in fig. 2, where the base of the combustion chamber is used as reference. A chromel-alumel type $\mathrm{K}$ thermocouple (indicated as $\mathrm{TC}_{\mathrm{hf}}$ in fig. 1) is located at the outlet of the cooling channel from the combustor, allowing to measure the temperature of the heated fuel. The accuracy of the thermocouples, provided by TC Thermocouples, is $0.75 \%$ of the full scale. As, following the presence of radiation errors, the temperature of a flame measured by means of thermocouples may significantly differ from the real one, all the measured temperatures have been corrected in order to obtain the real ones. The approach used to perform these corrections is detailed in paragraph 2.3.

The pressure transducers and the thermocouples are connected to a data acquisition system (National Instrument PXIe-1073) by means of two acquisition cards, respectively a National Instrument PXI-6229 for the pressure transducers (16-Bit, 32 analog inputs, 48 digital inputs/outputs) and a National Instrument PXIe-4353 for the thermocouples (32-Bit, 32 thermocouple input channels).

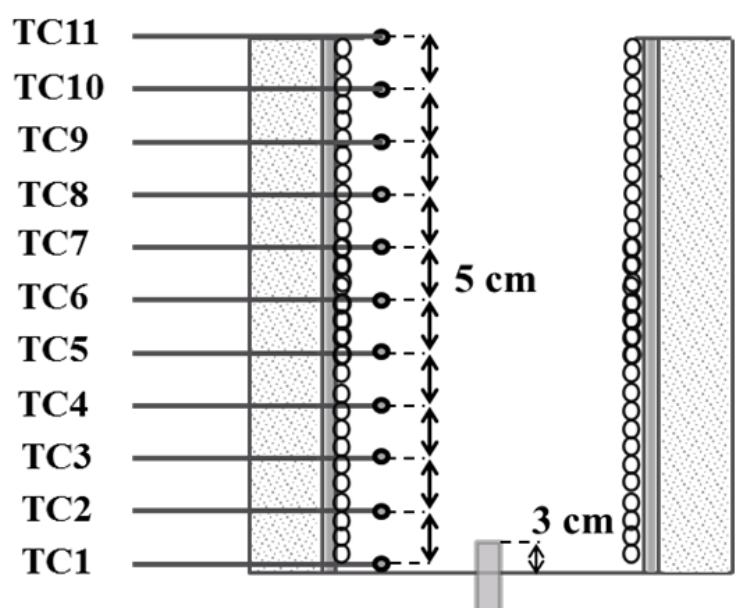

Figure 2. Scheme representing the position of the thermocouples measuring the combustion gases temperature

The experimental bench is completely automated; it can be controlled from a personal computer with an application created by using NI LabVIEW, which allows to open and to close each valve, to ignite and to turn off the burner, to start and to stop data acquisition. A video camera $(1280 \times 720$ pixels and 15 images/s $)$ is used to record a video of the flame during each test. Further details on the test bench have been given in a previous work [13]. 


\subsection{Test Methodology}

Tests are performed under both stationary and transient conditions. The pyrolysis of ethylene and consequent effects on heat transfer from the combustion gases to the combustor wall and to the cooling channel are investigated by varying two operating parameters that are fuel mass flow rate and fuel to oxidizer equivalence ratio. This equivalence ratio is modified by varying the ratio between ethylene mass flow rate and air mass flow rate. A brief review of the tests which are presented in this work is given in table 1.

The sequence of each test is programmed before its start using the LabVIEW application. Tests are carried out by varying a single input parameter, in order to determine its impact on the dynamics of the test bench. During each experiment, this parameter is increased twice and then decreased twice, while keeping the others constant. This enables catching the hysteresis phenomena whose presence has previously been detected by means of numerical calculations that have been detailed in a previous work [13]. Operating conditions are varied only when steady state has been achieved. For example, let us consider the case number 1. The test is started with a fuel mass flow rate of $0.020 \mathrm{~g} . \mathrm{s}^{-1}$, a fuel inlet pressure of $1 \mathrm{bar}$, and an equivalence ratio of 1.0; when steady state is achieved, the fuel mass flow rate is increased from 0.020 to 0.030 g.s ${ }^{-1}$ to let the system reach a new stationary state. In the same way, the fuel mass flow rate will be later increased to $0.040 \mathrm{~g} \cdot \mathrm{s}^{-1}$, then reduced twice respectively to 0.030 and 0.020 g.s $\mathrm{s}^{-1}$, to come back to the initial operating conditions. Meanwhile, fuel pressure and equivalence ratio are not modified. The combustor is assumed to be at steady state when the variation rate of the temperature of the fuel at the outlet of the cooling channel becomes lower than $0.1 \mathrm{~K} \cdot \mathrm{min}^{-1}$. Thus, during each experiment, the test bench achieves steady state five times. For simplicity purposes, they will be numbered consecutively, beginning from steady state 1 and finishing with steady state 5 .

\begin{tabular}{cccc}
\hline \hline $\begin{array}{c}\text { Test } \\
\text { case }\end{array}$ & $\begin{array}{c}\text { Fuel mass flow rate } \\
\left(\text { g.s }^{-1} \text { ) }\right.\end{array}$ & Equivalence ratio & $\begin{array}{c}\text { Fuel Inlet Pressure } \\
\text { (bar) }\end{array}$ \\
\hline 1 & $0.020-0.030-0.040$ & 1.50 & 1.0 \\
2 & $0.020-0.024-0.028$ & 1.00 & 1.0 \\
3 & $0.020-0.024-0.028$ & 1.25 & 1.0 \\
4 & $0.020-0.024-0.028$ & 1.50 & 1.0 \\
5 & 0.024 & $1.00-1.25-1.50$ & 5.0 \\
6 & $0.020-0.024-0.028$ & 1.00 & 4.0 \\
7 & $0.020-0.025-0.029$ & 1.25 & 5.0
\end{tabular}




\begin{tabular}{cccc}
8 & $0.020-0.024-0.029$ & 1.50 & 4.5 \\
9 & 0.016 & 1.25 & $5.00-8.0-11.0$ \\
\hline \hline
\end{tabular}

Table 1. Test cases for different operating conditions

At the start of each test, all the thermocouples are placed at $1 \mathrm{~cm}$ from the wall of the combustor, at position P1, with the exception, as already explained, of the two thermocouples indicated respectively as TC2 and TC7, which are placed at $5 \mathrm{~cm}$ from the wall, on the axis of the combustion chamber, at position P3 (fig. 3-a). When a steady state is achieved, the thermocouples which are at position P1 are first shifted at position P2 (at $3 \mathrm{~cm}$ from the wall, fig. 3-b), then at position P3 after the stabilization of the measured temperatures (fig.3-c). Before varying the input parameter whose effect is studied, the thermocouples which had been displaced are moved back to their original positions (fig. 3-d).

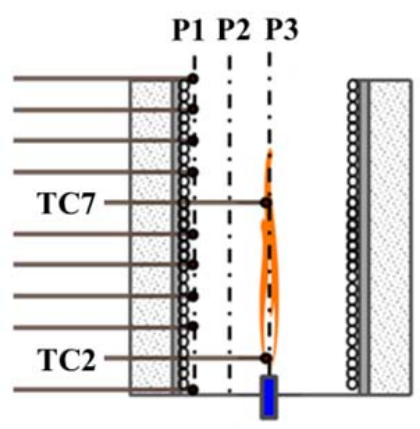

a)

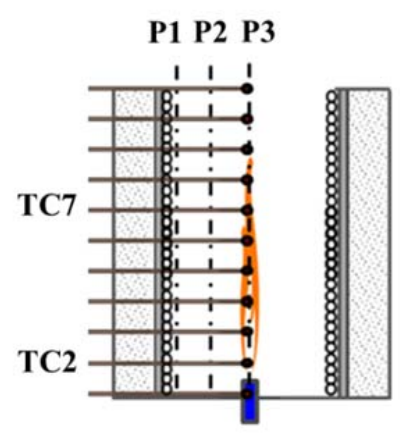

c)

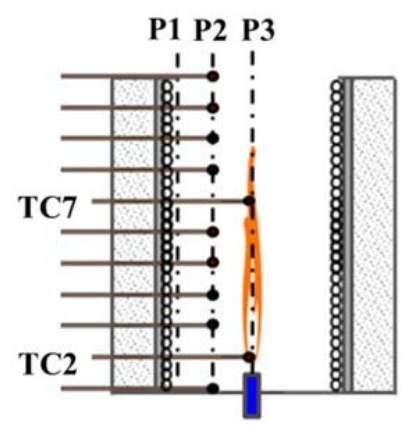

b)

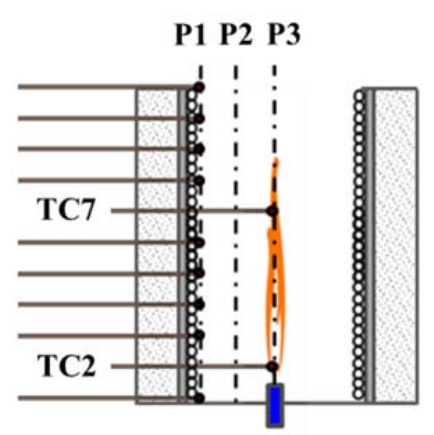

d)

Figure 3. Sequence representing how thermocouples are moved during each test

\subsection{Data Post-Processing}

After completing the tests, some post-processing has been done to ensure the reliability of experimental data. For example, because of the presence of radiation errors, the temperature of a flame measured by thermocouples may significantly differ from the real 
combustion gases temperature [47]. Radiation corrections of measured temperatures are not easy to perform; indeed, the quantification of radiation errors depends on various parameters such as the emissivity of the thermocouple, the temperature and the emissivity of the gases, the velocities of the gases in the vicinity of the thermocouple. To obtain the real burned gases temperatures, a steady-state heat transfer model, which can be applied to a bare-bead thermocouple, has been consider [49]. The following equation has been used:

$$
h_{t h} \cdot\left(T_{g}-T_{t h}\right)=\varepsilon_{t h} \cdot \sigma \cdot\left(T_{t h}^{4}-T_{w, i n t}^{4}\right)
$$

where $h_{\text {th }}$ is the convective heat transfer coefficient in the vicinity of the thermocouple, $T_{g}$ is the real gas temperature, $T_{t h}$ is the measured temperature, $\varepsilon_{t h}$ is the thermocouple emissivity (which is considered equal to 0.8 [47]), $\sigma$ is the Stefan-Boltzmann constant, $T_{w, \text { int }}$ is the temperature of the surrounding combustor wall. The above equation was chosen because it is widely used to correct radiation errors affecting combustion gases temperature measures $[47,49-52]$. To calculate $h_{\text {th }}$, the thermodynamic properties, the transport properties, and the velocities of the combustion gases must be known. The physical properties of the combustion gases have been determined by calculation on the basis of the composition and have been defined as a polynomial function of temperature. Burned gases composition is obtained by numerical calculations with the IdealGasReactor module of the CANTERA package [53] using as chemical reaction mechanism the one developed by Dagaut et al. [54]. The thermodynamic and transport properties of each constituent of the burned gases are taken from NIST website and from literature $[55,56]$. The velocities of the combustion gases in the combustor are determined with CFD software Fluent, considering a 2-D axisymmetric domain. Turbulence is modeled by using the standard k- $\varepsilon$ model, with standard wall functions near wall treatment $[57,58]$. For engineering purposes, this approach saves computational resources, as the viscosity affected near wall region does not need to be resolved. Grid independence has been verified.

The convective heat transfer coefficient $h_{\text {th }}$ has been calculated using the equation proposed by Whitaker et al. [59]:

$$
h_{t h}=\frac{k_{g, t h}}{D_{t h}} \cdot\left[2+\left(0.4 \cdot 0.06 \cdot R e_{t h}^{0.5}\right) R e_{t h}^{0.5}+R e_{t h}^{0.67} \cdot \operatorname{Pr}^{0.4}\right]
$$

where $\mathrm{Re}_{\text {th }}$ and $\mathrm{Pr}_{\text {th }}$ are defined as follows:

$$
R e_{t h}=\frac{\rho_{g, t h} \cdot D_{t h} \cdot v_{g, t h}}{\mu_{g, t h}}
$$




$$
P r_{t h}=\frac{C_{p, g t h} \cdot \mu_{g, t h}}{k_{g, t h}}
$$

In the above equations, $k_{g, t h}$ is the gas thermal conductivity, $D_{t h}$ is the thermocouple diameter, $\rho_{g, t h}$ is the gas density, $\mu_{g, t h}$ is the gas viscosity, $C_{p, g t h}$ is the gas specific heat, $v_{g, t h}$ is gas velocity. All the properties are calculated in the proximity of the thermocouple.

\section{Results and discussion}

\subsection{Influence on Combustor Dynamics of Fuel Mass Flow Rate: Study of a First Full Length Test}

The analysis of the influence of the operating parameters, fuel mass flow rate (indicated as $\dot{m}_{f}$ ) and equivalence ratio (indicated as $\varphi$ ), on the dynamics of the combustor represents a key challenge.

The schemes of fig. 4-a and 4-b, showing the effects of $\dot{m}_{f}$ and $\varphi$ on combustor dynamics, illustrate the complexity of this issue, due to the strong interaction between the physical and chemical phenomena that are involved. Fig. 4-a shows that $\dot{m}_{f}$ increases result in a decrease of fuel residence time in the cooling channel (indicated as $t_{f}$ ), leading to a loop whose effect on combustor dynamics are very difficult to predict. Similar considerations can be done on the scheme of fig. 4-b, showing that $\varphi$ increases result in flame emissivity increases that, in turn, result in a raise of the heat flux passing from the combustion gases to the combustor wall. Hence, the temperature of the fuel flowing in the cooling channel would increase, leading the system to the same loop of fig. 4-a. 


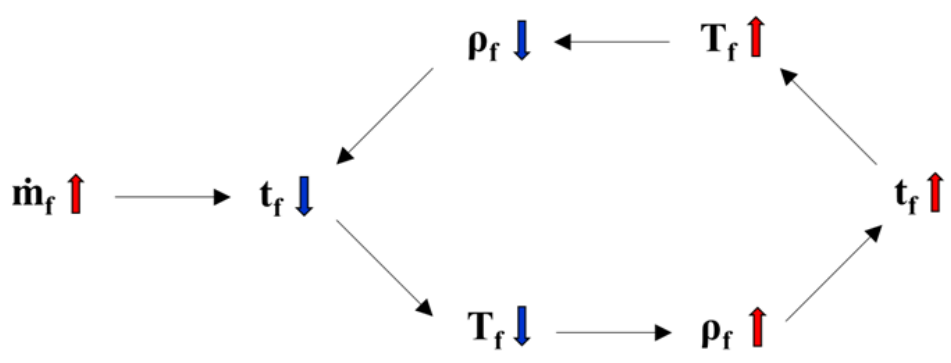

a)

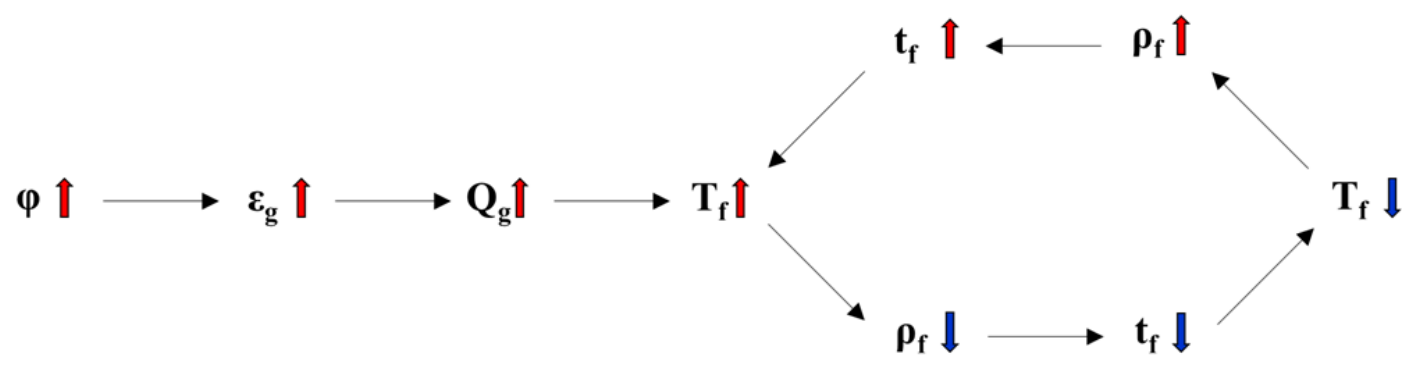

b)

Figure 4. Schemes showing the influence of $\dot{m}_{f}$ and $\varphi$ on combustion chamber dynamics

Fig. 4-a and fig. 4-b properly illustrate the difficulty of defining an engine regulation strategy permitting to assure the required thrust over the entire flight while securing a proper thermal management.

To facilitate the access of the reader to the wide data set that was collected during the experiments, a detailed analysis of one of the test cases is proposed (test case number 6 reported in table 1 , having a duration of $449.2 \mathrm{~min}$ ). A summary of the conditions under which this test has been conducted is given in table 2 . The experiment is run by varying a single input parameter, i.e. fuel mass flow rate, following the experimental procedure given in section 2. As it can be seen from table $2, \dot{m}_{f}$ is varied between 0.020 and 0.028 g.s ${ }^{-1}$. In order to assure a constant equivalence ratio $(\varphi=1)$, each time ethylene mass flow rate is varied, air mass flow rate is varied as well. The rate of variation of ethylene mass flow rate is set to 4.0 $\mathrm{kg} . \mathrm{s}^{-2}$ whereas the rate of variation of air mass flow rate is set to $12.5 \mathrm{~kg} . \mathrm{s}^{-2}$. The test is started at $t_{0}=4.2 \mathrm{~min}$ and is stopped at $t_{f}=453.4 \mathrm{~min}$.

\begin{tabular}{cccc}
\hline \hline $\begin{array}{c}\text { Time } \\
(\mathbf{m i n})\end{array}$ & $\begin{array}{c}\text { Change in } \\
\text { thermocouples position }\end{array}$ & $\begin{array}{c}\text { Change in fuel } \\
\text { mass flow rate } \\
\left(\text { g.s. }^{-1}\right)\end{array}$ & $\begin{array}{c}\text { Change in air } \\
\text { mass flow rate } \\
\left(\text { g.s }^{-1}\right)\end{array}$ \\
\hline 4.2 & \multicolumn{3}{c}{ Start of the test sequence } \\
\cline { 2 - 4 } 143.8 & P1 to P2 & - & -
\end{tabular}




\begin{tabular}{llcc}
147.2 & P2 to P3 & - & - \\
154.2 & P3 to P1 & 0.020 to 0.024 & 0.30 to 0.36 \\
223.2 & P1 to P2 & - & - \\
227.0 & P2 to P3 & - & - \\
235.1 & P3 to P1 & 0.024 to 0.028 & 0.36 to 0.42 \\
299.1 & P1 to P2 & - & - \\
302.0 & P2 to P3 & - & - \\
307.6 & P3 to P1 & 0.028 to 0.024 & 0.42 to 0.36 \\
374.0 & P1 to P2 & - & - \\
376.9 & P2 to P3 & - & - \\
384.5 & P3 to P1 & 0.024 to 0.020 & - \\
442.4 & P1 to P2 & - & - \\
445.3 & P2 to P3 & - & \\
453.4 & & End of the test Sequence & \\
\hline \hline
\end{tabular}

Table 2. Time events during the operation of test case number 6

The temperatures measured during test number 6 are reported, as a function of time, in fig. 5 and in fig. 6, representing respectively the burned gases temperature and the fuelcoolant temperature measured at the outlet of the cooling channel (measured by thermocouple $\mathrm{TC}_{\mathrm{hf}}$ and indicated as $T_{h f}$ ). To avoid crowding, fig. 5 only provides the temperatures measured by thermocouples TC2, TC4, TC6, TC8, and TC10, respectively at 3, 13, 23, 33, and $43 \mathrm{~cm}$ from the extremity of the burner, which is placed at $3 \mathrm{~cm}$ from the base of the combustor.

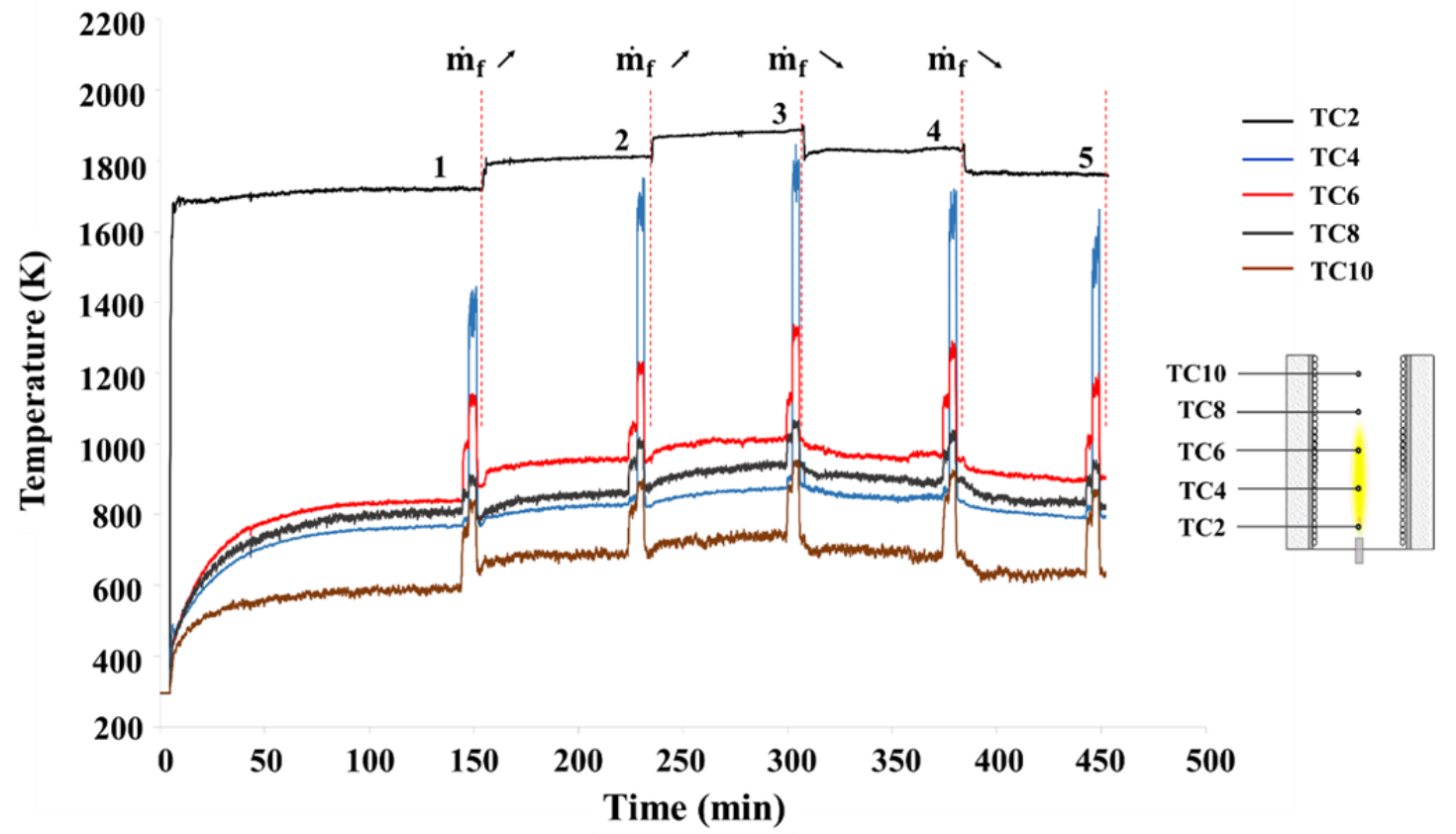

Figure 5. Variation of combustion gases temperatures with time for test 6 


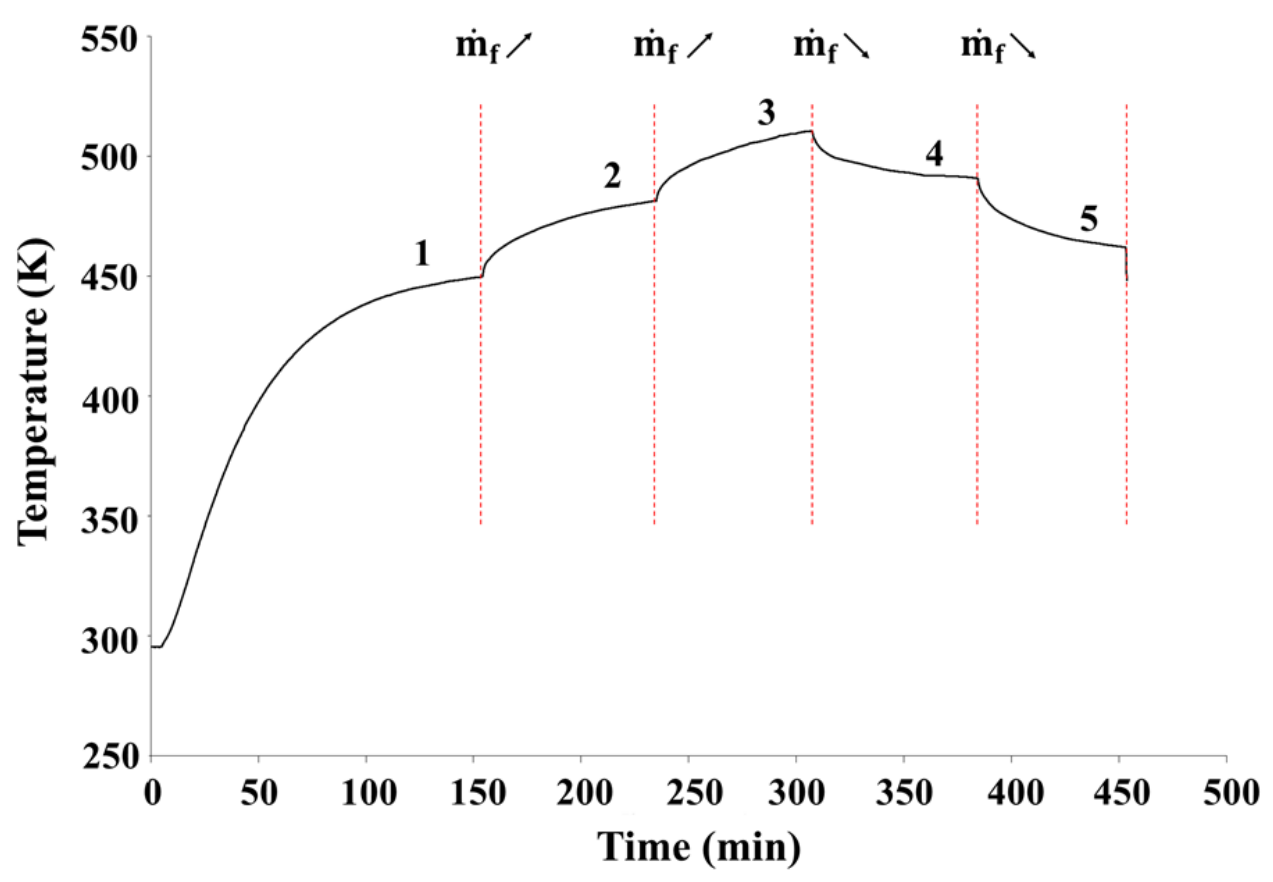

Figure 6. Variation of $T_{h f}$ with time for test 6

Both fig. 5 and 6 indicate that a raise of $\dot{m}_{f}$ leads to a raise of both burned gases and fuel-coolant temperaturs, while its drop leads to their decrease. This is consistent with literature works $[13,14]$. Figures 5 and 6 also show that the time needed to reach the first steady state, which is of $139.6 \mathrm{~min}$, is much higher than the times required to reach the next ones, which are between 58.4 (time to reach steady state 5) and $68.8 \mathrm{~min}$ (time to reach steady state 2). This is a consequence of the very high volumetric heat capacity of the combustion chamber. In fact, since at the start of each test the combustor is at ambient temperature, its heating needs a very long time. Then, when operating conditions are modified, the time required for the achievement of the following steady state is much lower because the system has already accumulated a significant amount of thermal energy.

It is important to observe that the maximum temperatures reached by the fuel-coolant in the cooling channel are probably higher than those shown in fig. 6, which are measured at the outlet of the rolled-up tube from the combustor (position 2 in fig. 1). Indeed, as shown below in fig. 8 in this paragraph, due to the peculiar temperature profile characterizing the combustion chamber, in the vicinity of its inner wall the temperatures achieved by the combustion gases tend to be higher at half of the combustor height, between 20 and $25 \mathrm{~cm}$ from its base. Consequently, it is approximately at half of the height of the combustor that the temperature reached by the fuel-coolant in the rolled-up cooling channel achieves its maximum value. Before reaching its outlet, where its temperature is measured by means of 
thermocouple $\mathrm{TC}_{\mathrm{hf}}$, the fuel passes through a colder region of the combustion chamber where it cools down because of the heat exchange between the fluid and the relatively colder combustor zones through which the rolled-up tube is passing [60].

The authors have tried to model the evolution of the fuel flowing in the cooling channel by means of numerical calculation carried out with the Plug Flow Reactor module of the CHEMKIN package. These calculations, which will be presented in a future paper, have shown that the maximum temperatures reached by the fuel-coolant are between $350 \mathrm{~K}$ and $450 \mathrm{~K}$ higher that the ones measured at its outlet. This explains why fuel decomposition has been observed despite the temperature measured by thermocouple $\mathrm{TC}_{\mathrm{hf}}$ is always lower than $750 \mathrm{~K}$ (which is too low to get ethylene pyrolysis [61-63]).

$T_{h f}$ values at steady state are shown in fig. 7. A hysteresis effect can be observed both by comparing steady state 1 and steady state 5 and by comparing steady state 2 and steady state 4. Indeed, fig. 7 shows that even in the presence of the same fuel mass flow rate $\left(0.020 \mathrm{~g} . \mathrm{s}^{-1}\right)$, the outlet fuel-coolant temperature at steady state $5\left(T_{h f, 5}=463.1 \mathrm{~K}\right)$ is higher than at steady state $1\left(T_{h f, 1}=448.7 \mathrm{~K}\right)$. The same applies with respect to steady state 2 and steady state 4 , being fuel mass flow rate the same $\left(0.024 \mathrm{~g} . \mathrm{s}^{-1}\right)$ and the outlet fuel-coolant temperatures different (respectively $T_{h f, 2}=480.0 \mathrm{~K}$ and $T_{h f, 4}=491.4 \mathrm{~K}$ ). This phenomenon, which results from the gap existing between the different time constants characterizing heat transfer by conduction, by convection and by radiation (which are, in the context of a fuel-cooled combustor, all involved), had already been numerically predicted [13]. Obviously, it further complicates the definition of a satisfactory engine control strategy as it makes it very difficult to develop analytical relationships between the physical and chemical parameters that must be taken into account in developing such a strategy.

$T_{h f}$ increases and decreases that occur as a result of $\dot{m}_{f}$ variations will be the object of a future work, where the most important heat fluxes characterizing the combustor (the heat flux density passing from the combustion gases to the combustor wall, the heat flux density absorbed by the fuel-coolant in the cooling channels, etc.), calculated by experimental data post-processing, will be presented. 


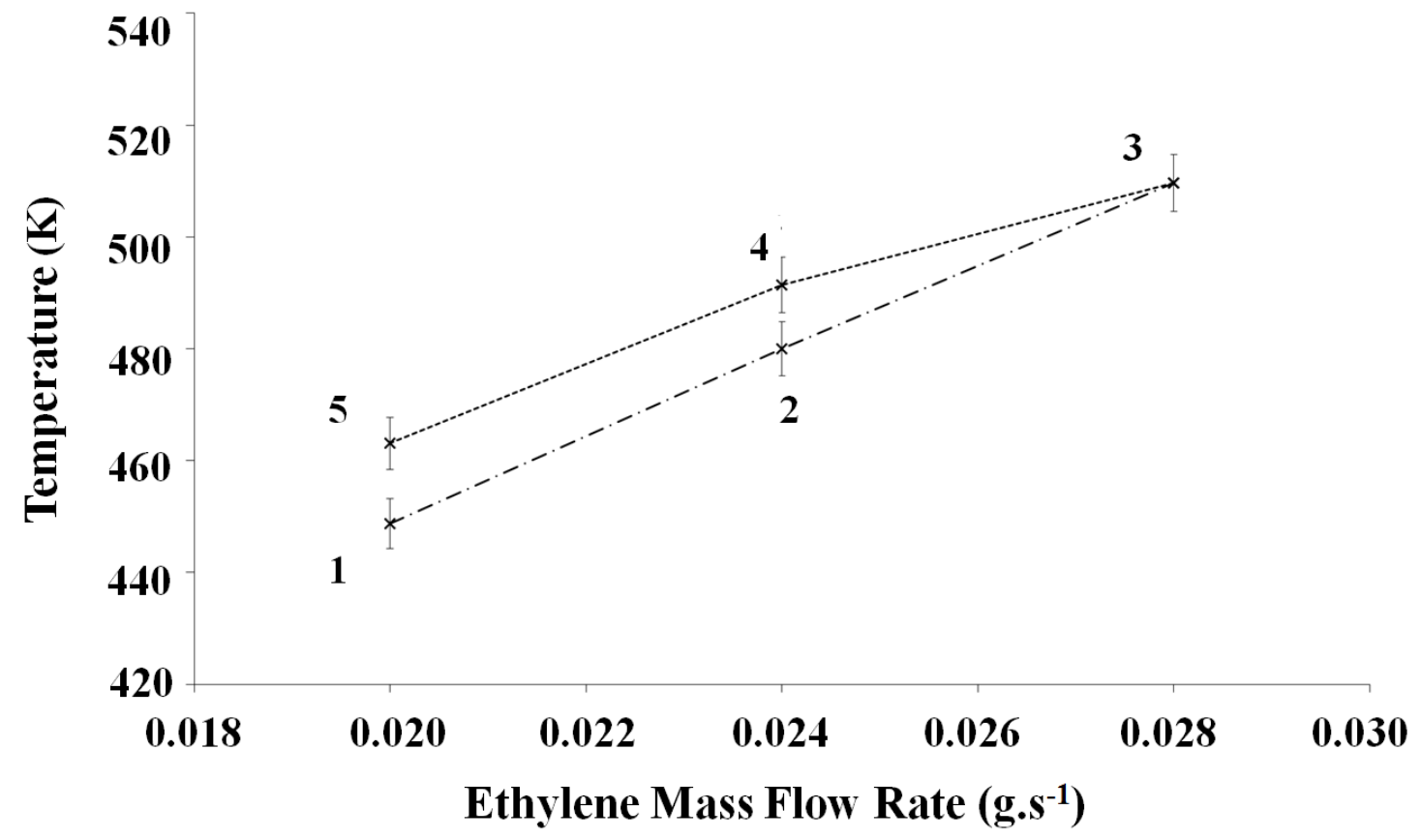

Figure 7. Variation of $T_{h f}$ with time for test 6

In fig. 8, the combustion gases temperatures along the axis are given for steady state conditions from 1 to 5 . For all the five plateaus, the higher temperature zone along the axis (position P3) is situated near the burner region (between 5 and $20 \mathrm{~cm}$ away from the base). As already mentioned above in this paragraph, in the zone between the axis and the wall (position P1 and P2), the temperatures tend to be higher at half of the combustor height (around $25 \mathrm{~cm}$ away from its base).

These findings are consistent with the results of previous experimental studies realized on a similar configuration [64]. In fact, as the burner is not equipped with any swirl, combustion gases recirculation in the downstream region of the combustion chamber is very weak; consequently, in this zone heat transfer from the flame to the gases beside it is essentially due to radiation. As these gases weekly absorb propagating radiation, their temperatures are, when compared to the combustion gases, quite low. 


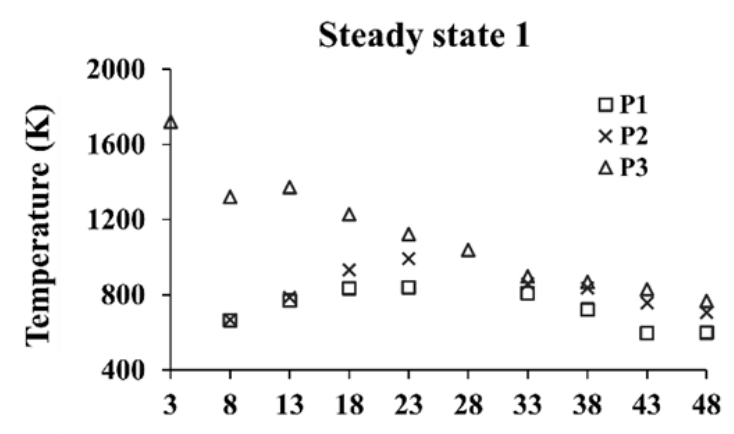

Distance from combustor base (cm)

a)

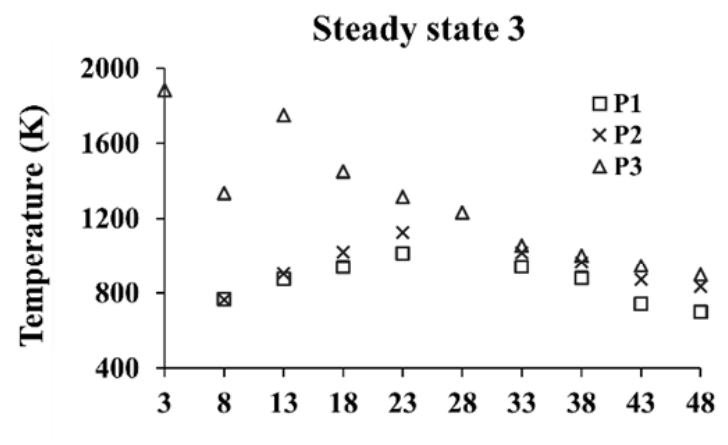

Distance from combustor base $(\mathrm{cm})$

c)

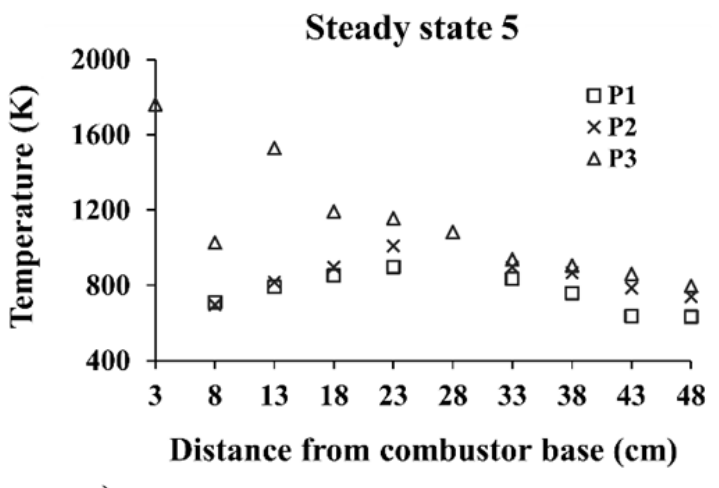

e)

Figure 8. Flame temperature profile along the axis at steady state for test 6

Data of fig. 8 also indicates that the temperature radial variations are greater near the region of the burner. Indeed, when moving from position P3 to position P1, the average radial variation for the five plateaus is $668.9 \mathrm{~K}$ between 10 and $15 \mathrm{~cm}$ from the base whereas it is $190.2 \mathrm{~K}$ between 40 and $45 \mathrm{~cm}$. This means that the fuel-coolant flowing in the cooling channel is mostly heated in the last part of the cooling channel, i.e. in the burner region.

One of the main parameters in the study of a fuel-cooled combustor is fuel-coolant residence time in the cooling channels. In the framework of this study, $t_{f}$ has been calculated with the following equation: 


$$
t_{f}=\frac{L_{c c}}{v_{f}}=\frac{L_{c c} \cdot \rho_{f} \cdot S_{c c}}{\dot{m}_{f}}
$$

In equation (5), $\mathrm{L}_{\mathrm{cc}}$ and $\mathrm{S}_{\mathrm{cc}}$ are respectively the length and the cross section of the cooling channel and $\rho_{f}$ is the fuel-coolant density.

Fuel residence time $t_{f}$ cannot be easily determined as it depends on fuel-coolant density that, in turn, depends on fuel composition and temperature, which are only known respectively at the inlet and at the outlet of the rolled-up tube. To determine fuel properties evolution along the tube, numerical calculations with ConstPressureReactor module of the CANTERA package have been performed. To this end, cooling channel pressure has been supposed to be equal to the average one between its inlet and its outlet. This allows to evaluate the variation of the fuel-coolant density and then to calculate its residence time by equation 5).

Results are given in fig. 9 as a function of fuel mass flow rate, for steady state plateaus from 1 to 5. The estimated values are between 6.75 and $7.07 \mathrm{~s}$. Despite a relative uncertainty in the calculated results of about $\pm 12 \%$, due to the assumptions made on pressure and to the difficulty of modeling the pyrolysis of ethylene, these outcomes permit to observe that $\dot{m}_{f}$ variations only weekly affect $t_{f}$. This result can be explained by the fact that, as this experiment has shown, $\dot{m}_{f}$ increases always result in $\rho_{f}$ increases whereas $\dot{m}_{f}$ decreases always result in $\rho_{f}$ decreases. Consequently, as it can be understood from equation 5), $\dot{m}_{f}$ variations do not influence $t_{f}$.

This outcome is very relevant. It is anyway important to note that probably it would not be valid if the fuel were a liquid as, if so, fuel mass flow rate variations would not result in fuel density changes.

In fig. 10, the rate of variation of the fuel-coolant temperature at cooling channel outlet (represented by the derivative of fuel-coolant temperature, indicated as $d T_{h f} d t$ ) is given as a function of time. 


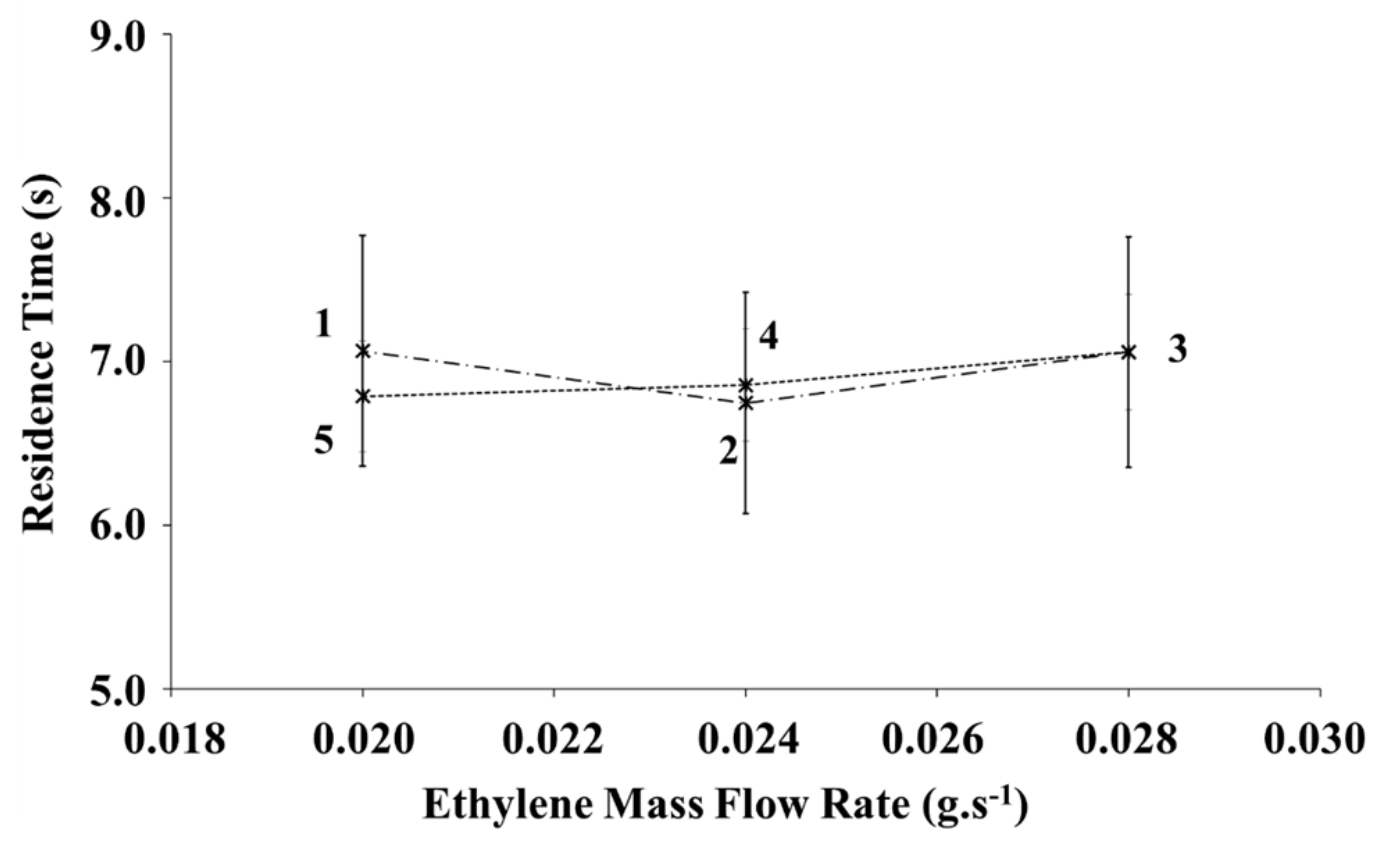

Figure 9. Fuel residence time $t_{f}$ as a function of mf at steady state for test 6

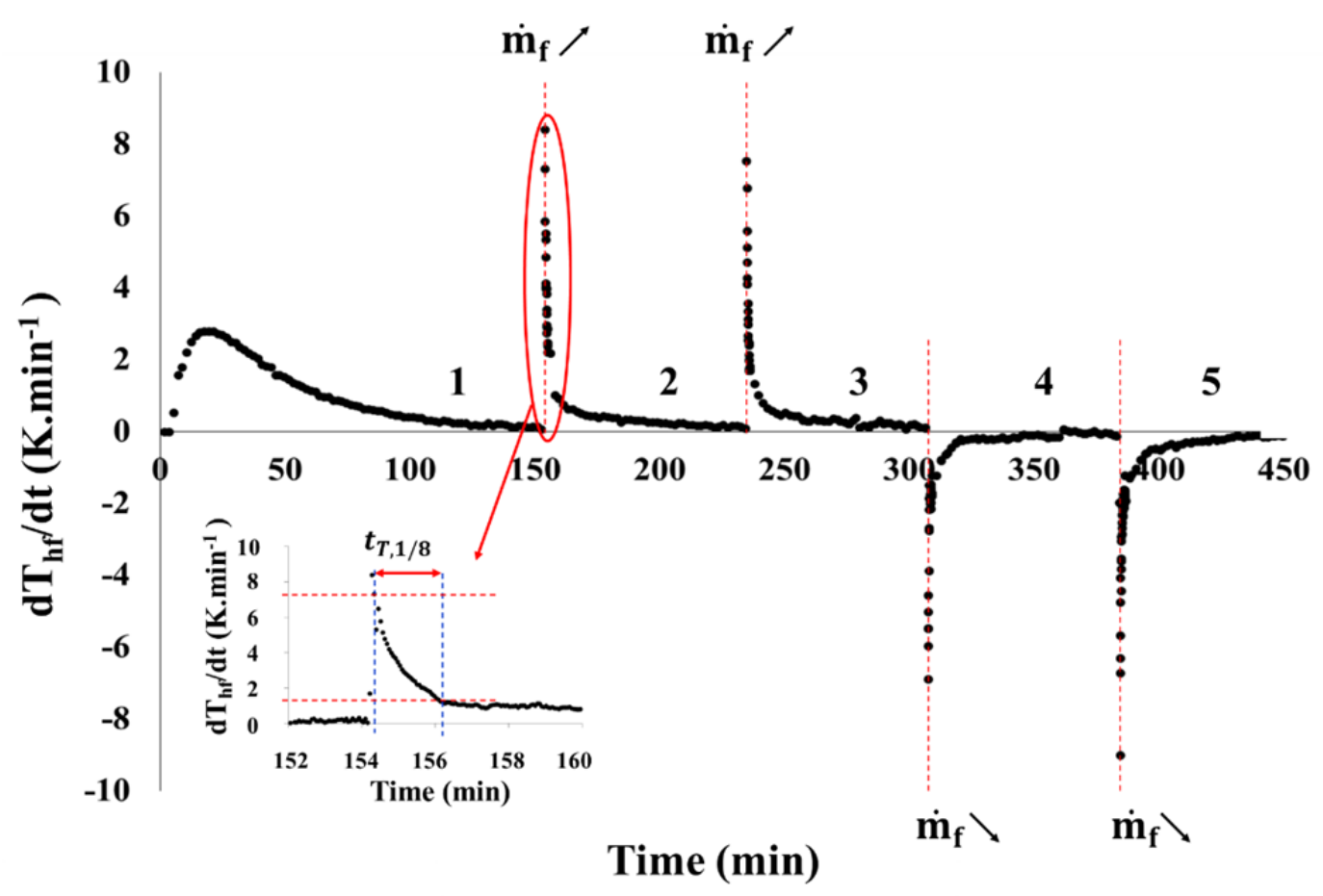

Figure 10. Variation of $d T_{h f} / d t$ with time for test 6

During the first 10 minutes this parameter increases, reaching a maximum of 2.95 K. $\mathrm{min}^{-1}$, following the global heating of the combustion chamber. Then, it remains stable for approximately 5 minutes before starting to decrease, until the achievement of a steady state. Fig. 10 indicates that $d T_{h f} d t$ is strongly affected by $\dot{m}_{f}$ variations. For example, when $\dot{m}_{f}$ is 
increased from 0.020 to 0.024 g.s ${ }^{-1}, d T_{h f} / d t$ raises from 0.07 to $8.39 \pm 1.26 \mathrm{~K} . \mathrm{min}^{-1}$ whereas when $\dot{m}_{f}$ is increased from 0.024 to $0.028 \mathrm{~g} . \mathrm{s}^{-1}$, it raises from 0.08 to $7.51 \pm 1.13 \mathrm{~K} \mathrm{~min}^{-1}$. In any case, if the absolute values are considered, it can be remarked that during the transient evolution of the system they always gradually decay, as the system tends to a steady state. It is important to stress that it is quite difficult to establish the reliability of above given $d T_{h f} / d t$ variations as their determination relies on the acquisition of a single data point. Thus, with a higher sampling frequency, the results could be different.

The analysis of the derivative of fuel-coolant temperature $d T_{h f} / d t$ also allows to estimate system response time to fuel mass flow rate variations (indicated as $t_{\text {resp }}$ ). In this sense, the data of table 3 show that $t_{\text {resp }}$ is lower than $t_{f}$ (of about 40 to $50 \%$ ) when fuel flow rate is increased whereas it is very close to $t_{f}$ when fuel flow rate is decreased.

In fig. 11, the time derivative of fuel pressure at cooling channel inlet (indicated as $d P_{f}(d t)$, is presented as a function of time.

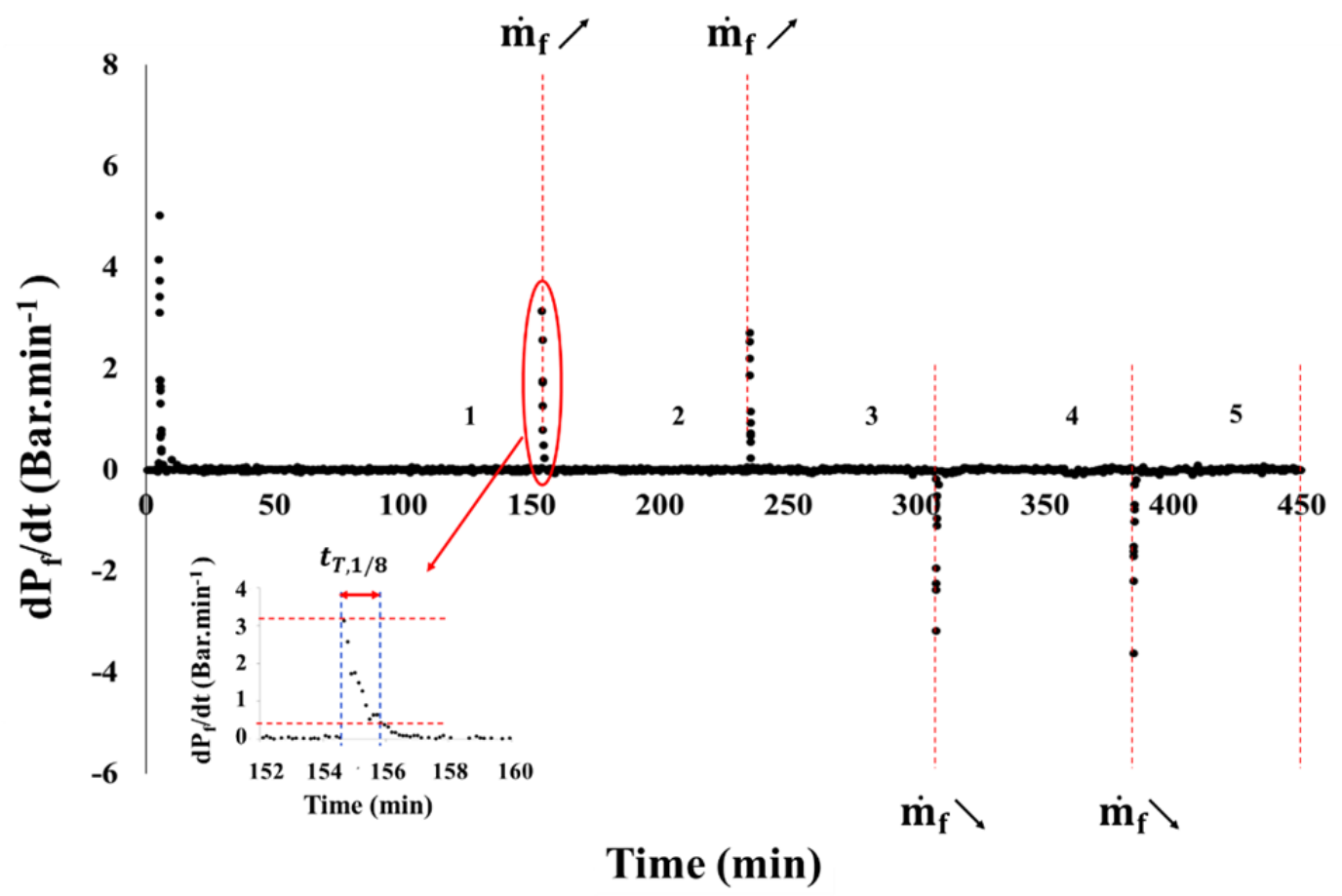

Figure 11. Variation of $d P_{f} / d t$ with time for test 6

Complementarily, table 4 provides the empirical values corresponding to the times needed for $d T_{h f} d t$ and for $d P_{f} / d t$ to reach one in eight of the maximum values achieved after mass flow variations (they are indicated respectively as $t_{T, 1 / 8}$ and $t_{P, 1 / 8}$ ). It is clear from table 4 that the dynamics of the hydraulic flow in the cooling channel are much faster than the thermal ones (of a factor of about 10). 


\begin{tabular}{cccc}
\hline $\begin{array}{c}\text { Time } \\
(\mathbf{m i n})\end{array}$ & $\begin{array}{c}\text { Fuel mass flow rate } \\
\left(\mathbf{g . s}^{-\mathbf{1}}\right)\end{array}$ & $\boldsymbol{t}_{\text {resp }}$ (s) & $\boldsymbol{t}_{\boldsymbol{f}}$ (s) \\
\hline 154.2 & 0.020 to 0.024 & $3.54 \pm 1.06$ & $6.78 \pm 0.61$ \\
235.1 & 0.024 to 0.028 & $3.48 \pm 1.04$ & $6.85 \pm 0.62$ \\
307.6 & 0.028 to 0.024 & $6.98 \pm 1.95$ & $7.06 \pm 0.65$ \\
384.5 & 0.024 to 0.020 & $7.02 \pm 2.11$ & $7.07 \pm 0.61$ \\
\hline \hline
\end{tabular}

Table 3. Comparison between system response time and fuel residence time in the cooling channel for test 6

\begin{tabular}{cccc}
\hline $\begin{array}{c}\text { Time } \\
\text { (min) }\end{array}$ & $\begin{array}{c}\text { Change in ethylene } \\
\text { mass flow rate } \\
\left.\text { (g.s } \mathbf{s}^{-1}\right)\end{array}$ & $\boldsymbol{t}_{T, 1 / 8}(\mathbf{s})$ & $\boldsymbol{t}_{\boldsymbol{P}, 1 / 8} \mathbf{( s )}$ \\
\hline 154.2 & 0.020 to 0.024 & 133.8 & 30.0 \\
235.1 & 0.024 to 0.028 & 259.8 & 28.8 \\
307.6 & 0.028 to 0.024 & 239.4 & 33.0 \\
384.5 & 0.024 to 0.020 & 231.6 & 30.0 \\
\hline \hline
\end{tabular}

Table 4. Times $d T_{h f} d t$ and $d P_{f} d t$ need to reach $1 / 8$ of the maximum values after $\dot{m}_{f}$ variations

\subsection{Influence of Equivalence Ratio}

Due to the strong effect on fuel-coolant heating of the combustion gases temperature and emissivity, the influence of equivalence ratio $\varphi$, which can affect both, needs also to be investigated. To this end, the results of tests number 2 , number 3 , and number 4 are compared. Again, these tests are carried out by varying a single input parameter, i.e. $\dot{m}_{f}$, between 0.020 and 0.028 g.s ${ }^{-1}$.

To study the influence of $\varphi$, three different equivalence ratio values are chosen, respectively 1.0 for test number $2,1.25$ for test number 3 , and 1.5 for test number 4 . The rates of variation of ethylene and air mass flow rate are the same as in experiment 6 . With regard to case $4(\varphi=1.5)$, data are only available for steady state plateaus from 1 to 3 . Indeed, during this experiment, the decomposition of the fuel has originated coke deposits that have caused the occlusion of the cooling channel and the interruption of the test before its end. Hence, plateaus 4 and 5 are not available.

The values reached by $T_{h f}$ at steady state by the fuel-coolant at the outlet of the cooling channel for these three experiments are given in fig. 12. 


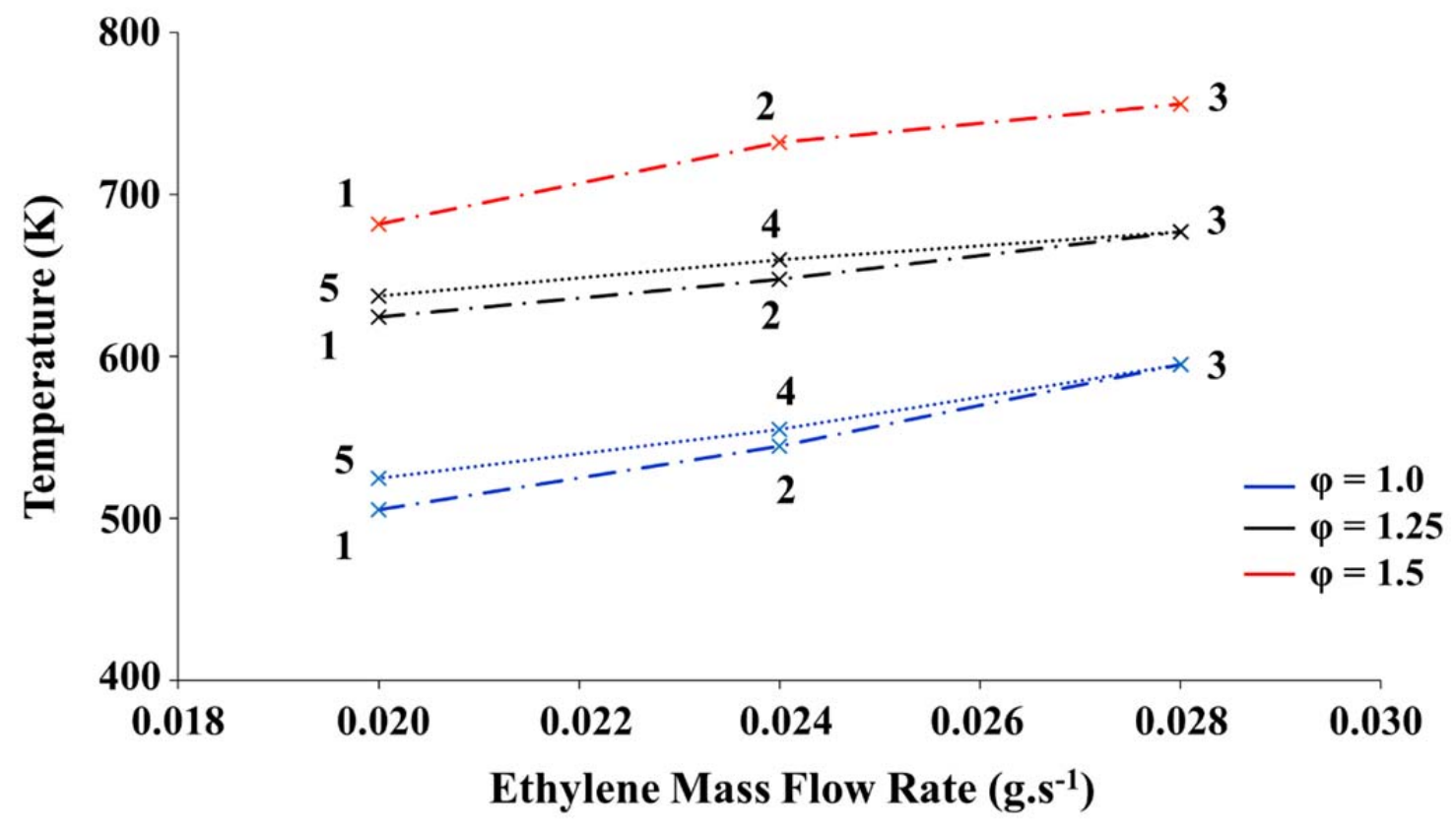

Figure 12. $T_{h f}$ at steady state for tests 2,3 , and 4

It can be seen that they linearly increase with $\varphi$. This cannot be justified on the basis of fuel residence time variations, as it can be seen from table 5, which gives for the three test cases the average values of this parameter along the test. The data of table 5 indicate that $t_{f}$ higher values are reached in the case of a stoichiometric combustion, when $T_{h f}$ values are the lower ones. Indeed $T_{h f}$ increases with $\varphi$ can rather be explained by considering that even a small increase in this parameter results in a substantial increase in the heat flux passing from the burned gases to the combustor wall, due to the formation of soot which determines the growth of flame emissivity and of the radiative heat flux [65-67]. These outcomes will be widely discussed in a future paper.

\begin{tabular}{ccc}
\hline $\begin{array}{r}\text { Test } \\
\text { case }\end{array}$ & $\boldsymbol{\varphi}$ & $\boldsymbol{t}_{\boldsymbol{f}}(\mathbf{s})$ \\
\hline 2 & 1 & $3.78 \pm 0.41$ \\
3 & 1.25 & $3.12 \pm 0.38$ \\
4 & 1.5 & $3.16 \pm 0.37$ \\
\hline \hline
\end{tabular}

Table 5. Average residence times at steady state for tests 2, 3, and 4

Fig. 13, which illustrates, respectively for case 2, 3, and 4, some pictures of the flame, confirms that an increase in the fuel to oxidizer equivalence ratio results in an increase in flame luminosity. It shows that the flames of case 2 and case 3, due to incandescence of 
the soot generated under fuel-rich conditions, are yellow, while the flame of case 4 is blue as no radiating soot is produced [67].

In table $6, d T_{h f} / d t$ variations occurring after $\dot{m}_{f}$ variations (which are referred to respectively as $d T_{h f} / d t_{1}, d T_{h f} d d t_{2}, d T_{h f} / d t_{3}$ and $\left.d T_{h f} / d t_{4}\right)$ are given. The data of this table indicate that all these derivatives strongly increase with the increasing of $\varphi$.

These outcome is of major importance as they show that test bench dynamics are strongly influenced by the ratio between fuel and oxidizer mass flow rates. Under fuel-rich conditions, when, as it is discussed in the second part of the paper, heat transfer by radiation becomes predominant compared to convection heat transfer, system response in terms of fuelcoolant temperature variation is more accentuated.

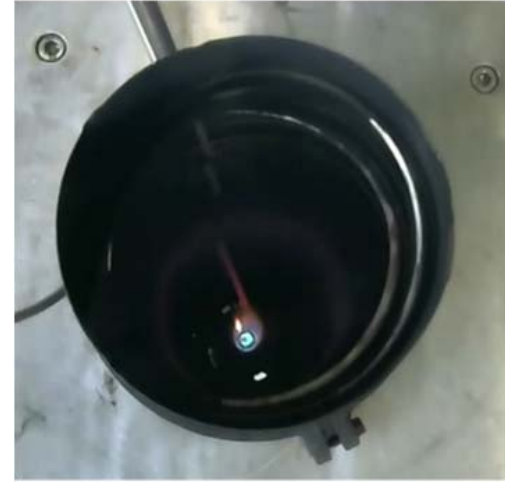

a)

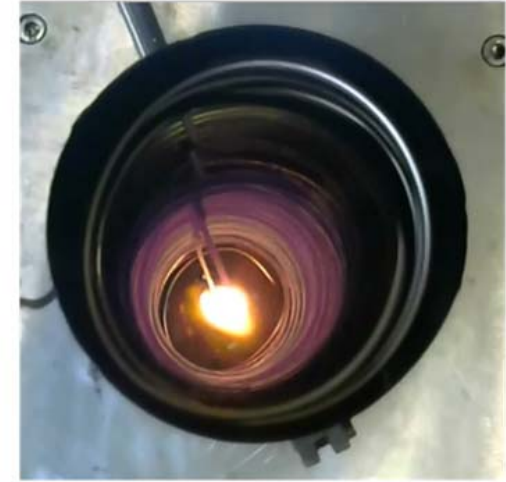

b)

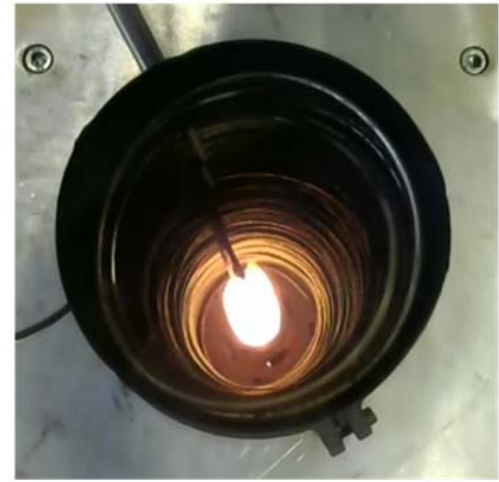

c)

Figure 13. Pictures of the flame for $\varphi=1.0$ (a), $\varphi=1.25$ (b), and $\varphi=1.5$ (c)

Differently from the fuel heating rate, no evidence of an influence of $\varphi$ on the rate of variation of fuel pressure $d P_{f} / d t$ is observed. This shows that the hydraulic part is mostly influenced by the coolant flow rate, at least more than by the equivalence ratio.

\begin{tabular}{|c|c|c|c|c|c|c|}
\hline $\begin{array}{l}\text { Test } \\
\text { case }\end{array}$ & $\varphi$ & $\begin{array}{c}d T /\left.d t\right|_{\max } \\
\left(\mathrm{K} . \mathrm{s}^{-1}\right)\end{array}$ & $\begin{array}{l}d T /\left.d t\right|_{1} \\
\left(K . s^{-1}\right)\end{array}$ & $\begin{array}{l}d T /\left.d t\right|_{2} \\
\left(\mathrm{~K} . \mathrm{s}^{-1}\right)\end{array}$ & $\begin{array}{l}d T /\left.d t\right|_{3} \\
\left(\mathrm{~K} . \mathrm{s}^{-1}\right)\end{array}$ & $\begin{array}{l}d T /\left.d t\right|_{4} \\
\left(\mathrm{~K} . \mathrm{s}^{-1}\right)\end{array}$ \\
\hline 2 & 1.0 & 2.78 & $13.69 \pm 2.05$ & $10.65 \pm 1.60$ & $-10.68 \pm 1.60$ & $-12.12 \pm 1.82$ \\
\hline 3 & 1.25 & 6.86 & $30.85 \pm 4.63$ & $27.17 \pm 4.08$ & $-22.12 \pm 3.32$ & $-24.60 \pm 3.69$ \\
\hline 4 & 1.5 & 9.60 & $33.12 \pm 4.97$ & $36.66 \pm 5.50$ & - & - \\
\hline
\end{tabular}

Table 6. Fuel heating rate variations following fuel flow rate variations for tests 2,3 , and 4

\section{Conclusions}


Regenerative cooling by the on-board hydrocarbon fuel is a widely applied cooling technique suitable to secure the thermal protection of supersonic combustion air-breathing vehicles flying above Mach 5. Due to the complexity of the phenomena which are involved (heat transfers, phase transitions, chemical reactions), this technology needs to be investigated by an experimental approach permitting to validate the numerically acquired knowledge and to understand its dynamics. Hence, a regeneratively cooled combustor has been designed. Experiments are performed under both stationary and transient conditions using ethylene as fuel and air as oxidizer. The effect of two major parameters, i.e. the fuel mass flow rate and the equivalence ratio, on flame temperature field, coolant pressure and coolant temperature has been determined. It has been shown that a higher fuel mass flow rate results in an increase in flame temperatures, coolant temperature and coolant pressure. This clearly demonstrates that the management of engine cooling by the fuel is a real challenge because it is absolutely counter-intuitive in classical heat exchangers to observe that coolant temperature increases with coolant flow rate. It has also been demonstrated that equivalence ratio increases lead to a raise of coolant temperature, due to a raise of the radiative heat flux passing from the burned gases to the combustor wall. This point is of particular interest for engineering design because it illustrates the need to control the burning process and its homogeneity in order to avoid local fuel-rich conditions. A hysteresis effect due to heat transfer dynamics has been found; this is in good agreement with previous numerical predictions. The characteristic times of the commands (few seconds to change fuel mass flow rate and equivalence ratio) and of system response are far smaller than the characteristic time of thermal stabilization in this channel (in the range from about 140 to 240 s corresponding to a renewal of the channel of approximately 50-70 times). It has also been observed that the raise of fuel flow rate has a greater quantitative impact on the coolant temperature (which rises) in case of fuel-rich conditions compared to stoichiometric ones. In a future work, the effects of fuel mass flow rate and fuel to oxidizer equivalence ratio on the heat flux density passing from the combustion gases to the combustor wall, the sensible heat flux absorbed by the fuel-coolant, the heat loss due to the exhaust gases and the heat loss due to heat transfer from the combustor external surface to the surrounding environment will be analyzed. The heat transfer efficiency of the combustor will be defined and its dependence upon fuel mass flow rate and fuel to oxidizer equivalence ratio will be presented.

\section{References}


[1]Van Wie D. M., D’Alessio S. M., and White M. E. "Hypersonic Air breathing Propulsion," Johns Hopkins APL Technical Digest, vol. 26, 2005, pp. 430-436.

Doi: $10.2514 / 4.470356$

[2]Fry, R. S., “A Century of Ramjet Propulsion Technology Evolution," Journal of Propulsion and Power, vol. 20, 2004, pp. 27-58.

Doi: $10.2514 / 1.9178$

[3]Curran, E. T., "Scramjet Engines: The First Forty Years," Journal of Propulsion and Power, vol. 17, 2001, pp. 1138-1148.

Doi: $10.2514 / 2.5875$

[4]Van Griethuysen, Glickstein, M. R., Petley, M. R., Gladden D. H., and Kubik, D. L., "High-Speed Flight Thermal Management", Developments in High-Speed Vehicle Propulsion Systems, in Progress in Aeronautics and Astronautics, vol. 165, 1996, pp. 517 579.

Doi: $10.2514 / 5.9781600866401 .0517 .0579$

[5]Ulas, A., and Boysan, E., "Numerical analysis of regenerative cooling in liquid propellant rocket engines," Aerospace Science and Technology, vol. 24, 2013, pp. 187-197.

Doi: 10.1016/j.ast.2011.11.006

[6]Hou, L. Y., Dong, N., and Sun, D. P., "Heat transfer and thermal cracking behavior of hydrocarbon fuel," Fuel, vol. 103, 2013, pp. 1132-1137.

Doi: 10.1016/j.fuel.2012.09.021

[7]Maurice, L., Edwards, T., and Griffits, J., "Liquid Hydrocarbon Fuels for Hypersonic Propulsion," in Scramjet Propulsion, Progress in Aeronautics and Astronautics, vol. 189, 2001, pp. 757-822.

Doi: $10.2514 / 5.9781600866609 .0757 .0822$

[8]Veraar, R. G., "Ramjets : Thermal Management - An Integrated Engineering Approach," NATO Science and Technology Organization, 2010.

[9]Heiser, W. H., and Pratt, D. T, "Hypersonic Air-breathing Propulsion", edited by J.S. Przemieniecki, in Progress in Astronautics and Aeronautics, Washington DC, 1994.

Doi: $10.2514 / 4.470356$ 
[10]Bao, W., Li, X., Qin, J., Zhou, W., and Yu, D., "Efficient Utilization of Heat Sink of Hydrocarbon Fuel For Regeneratively Cooled Scramjet," Applied Thermal Engineering, vol. 33-34, 2012, pp. 208-218.

Doi: 10.1016/j.applthermaleng.2011.09.036

[11] Bouchez, M., "Scramjet Thermal Management Scramjets or Dual Mode Ramjets for High Speed Atmospheric Flight,” NATO Science and Technology Organization, 2010.

[12] Sobel, D. R., and Spadaccini, L. J., "Hydrocarbon Fuel Cooling Technologies for Advanced Propulsion," Journal of Engineering for Gas Turbines and Power, vol. 119, 1997, pp. 344-351.

Doi: $10.1115 / 1.2815581$

[13] Gascoin, N., and Gillard, P., "Dynamic Study of Coupled Heavy Hydrocarbon Pyrolysis and Combustion," Combustion Science and Technology, vol. 184, 2012, pp. 2136-2153.

Doi: $10.1080 / 00102202.2012 .703729$

[14] Taddeo, L., Gascoin, N., Fedioun, I., Chetehouna, K., Lamoot, L., and Fau, G., "Dimensioning of automated regenerative cooling: Setting of high-end experiment," Aerospace Science and Technology, vol. 43, 2015, pp. 350-359.

Doi: 10.1016/j.ast.2015.03.015

[15] Feng, Y., Qin, J., Zhang, S., Bao, W., Cao, Y., and Huang, H., "Modeling and analysis of heat and mass transfers of supercritical hydrocarbon fuel with pyrolysis in mini-channel," International Journal of Heat and Mass Transfer, vol. 91, 2015, pp. 520-531.

Doi: 10.1016/j.ijheatmasstransfer.2015.07.095

[16] Serre, L., and Falempin, F., "The French PROMETHEE program on hydrocarbon fueled dual mode ramjet Status in 2001," AIAA/NAL-NASDA-ISAS 10th International Space Planes and Hypersonic Systems and Technologies Conference, Huntsville, Texas, April 24-27, 2001.

Doi: doi:10.2514/6.2001-1871

[17] Drummond, J. P., Bouchez, M., McClinton, “CHAPTER 1: OVERVIEW OF NATO BACKGROUND ON SCRAMJET TECHNOLOGY," Technologies for Propelled Hypersonic Flight, NATO Science and Technology Organization, 2010. 
[18] Gascoin, N., Gillard, P., Dufour, E., and Touré, Y., "Validation of Transient Cooling Modeling for Hypersonic Application," Journal of Thermophysics and Heat Transfer, vol. 21, 2007, pp. 86-94.

Doi: $10.2514 / 1.26022$

[19] Kirchberger, C., Wagner, R., Kau, H-P., Soller, S., Martin, P., Bouchez, M., and Bonzom, C., "Prediction and Analysis of Heat Transfer in Small Rocket Chambers," 46th AIAA Aerospace Sciences Meeting and Exhibit, Reno, January 7-10, 2008.

Doi: $10.2514 / 6.2008-1260$

[20] Dufour, E., and Bouchez, M., "Post-Experimental computations of a kerosene-fueled scramjet", 10th AIAA/NAL-NASDA-ISAS International Space Planes and Hypersonic Systems and Technologies Conference, Kyoto, Japan, April 24-27, 2001.

Doi: $10.2514 / 6.2001-1817$

[21] Frankel, J. I., Keyhani, M., Elkins, B., and Arimilli, R. V., "New In Situ Method for Estimating Thermal Diffusivity Using Rate-Based Temperature Sensors," Journal of Thermophysics and Heat Transfer, vol. 24, 2010, pp. 811-817.

Doi: $10.2514 / 1.46300$

[22] Parris, D. K., and Landrum, D. B., "Effect of Tube Geometry on Regenerative Cooling Performance," 41st AIAA/ASME/SAE/ASEE $41^{\text {st }}$ Joint Propulsion Conference and Exhibit, Tucson, Arizona, July 10-13, 2005.

Doi: $10.2514 / 6.2005-4301$

[23] Yagley, J., Feng, J., and Merkle, C. L., "The effect of Aspect Ratio on the Effectiveness of Combustor Coolant Passages," AIAA/SAE/ASME/ASEE $28^{\text {th }}$ Joint Propulsion Conference and Exhibit, Nashville, Tennessee ,July 6-8, 1992.

Doi: $10.2514 / 6.1992-3153$

[24] Bao, W., Qin, J., Zhou, W. X., and Yu, D. R., "Effect of cooling channel geometry on recooled cycle performance for hydrogen fueled scramjet," International Journal of Hydrogen Energy, vol. 35, 2010, pp. 7002-7011.

Doi: 10.1016/j.ijhydene.2010.04.033

[25] Wadel, M.F., "Comparison of High Aspect Ratio Cooling Channel Designs for a Rocket Combustion Chamber," AIAA/ASME/SAE/ASEE, 33 ${ }^{\text {rd }}$ Joint Propulsion Conference, Seattle, July 06-09, 1997. 
Doi: $10.2514 / 6.1997-2913$

[26] Pizzarelli, M., Nasuti, F., and Onofri, M., "Trade-off analysis of high-aspect-ratiocooling-channels for rocket engines," International Journal of Heat and Fluid Flow, vol. 44, 2013, pp. 458-467.

Doi: 10.1016/j.ijheatfluidflow.2013.08.003

[27] Medwick, D.G., Castro, J.H., Sobel, D.R., Boyet, G., Vidal, J.P., "Direct fuel cooled composite structure" XIV International Symposium on Air Breathing Engines (ISABE), Florence, September 5-10, 1999.

[28] Peres, P, Lansalot, J., Bouchez, M., and Saunier, E. "Advanced carbon-carbon injection struts for actual scramjet," AIAA Space Plane and Hypersonic Systems and Technology Conference, Norfolk, Virginia, November 18-22, 1996.

Doi: $10.2514 / 6.1996-4567$

[29] Johnson, S.J., Adharapurapu, R.R., Pollock, T.M., "Post-Fabrication Vapor Phase Strengthening of a Nickel-Based Sheet Alloy for Thermo-Structural Panels," Acta Materialia, vol. 56, 2008, pp. 4577-4584.

Doi: 10.1016/j.actamat.2008.05.013

[30] Evans, A. G., Zok, F. W., Levi C. G., McMeeking, R. M., Miles, R. M., and Pollock, T. M., "Revolutionary materials for hypersonic flight," University of California Final Technical Report, October 2011.

[31] Falempin, F., "The French PROMETHEE Program on Hydrocarbon Fueled Dual Mode Ramjet: Status in 2001," AIAA/CIRA 13th International Space Planes and Hypersonics Systems and Technologies, Capua, May 16-20, 2005.

Doi; $10.2514 / 6.2001-1871$

[32] Daniau, E., and Sicard, M., "Experimental and numerical investigations of an endothermic fuel cooling capacity for scramjet application," AIAA/CIRA 13th International Space Planes and Hypersonics Systems and Technologies, Capua, May 1620, 2005.

Doi: $10.2514 / 6.2005-3404$

[33] Vincent-Randonnier, A., Rouxel, B., Roux, P., Poirot, M., Sicard, M., Raepsaet, B., and Ser, F., "Experimental Investigations on the Self-Ignition of a Thermally Decomposed Endothermic Fuel in Hot Supersonic Air Flow in the MPP-LAERTE Combustion Test 
Bench," 15th AIAA International Space Planes and Hypersonic Systems and Technologies Conference, Dayton, Ohio, April 28 - May 1, 2008.

Doi: $10.2514 / 6.2008-2676$

[34] Abraham, G., Gascoin, N., Gillard, P., and Bouchez, M., "Real-time method for the identification and quantification of hydrocarbon pyrolysis products: Part I. Development and validation of the infrared technique," Journal of Analytical and Applied Pyrolysis, vol. 91, 2011, pp. 368-376.

Doi: 10.1016/j.jaap.2011.03.014

[35] Gascoin, N., Abraham, G., Gillard, P., and Bouchez, M., "Real-time method for the identification and quantification of hydrocarbon pyrolysis products: Part II. Application to transient pyrolysis and validation by numerical simulation," Journal of Analytical and Applied Pyrolysis, vol. 91, 2011, pp. 377-387.

Doi: 10.1016/j.jaap.2011.04.005

[36] Song, C., Eser, S., Schobert, H. H., and Hatcher, P. G., "Pyrolytic degradation studies of a coal-derived and a petroleum-derived aviation jet fuel," Energy \& Fuels, vol. 7, 1993, pp. 234-243.

Doi: 10.1016/j.jaap.2013.06.007

[37] Chin, J. S., and Lefebvre, a. H., "Influence of Flow Conditions on Deposits from Heated Hydrocarbon Fuels," Journal of Engineering for Gas Turbines and Power, vol. 115, 1993, pp. 433-438.

Doi: $10.1115 / 1.2906727$

[38] Sobel, D. R., and Spadaccini, L. J., "Hydrocarbon Fuel Cooling Technologies for Advanced Propulsion," Journal of Engineering for Gas Turbines and Power, vol. 119, 1997, pp. 344-351.

Doi: $10.1115 / 1.2815581$

[39] Spadaccini, L. J., Sobel, D. R., and Huang, H., "Deposit Formation and Mitigation in Aircraft Fuels," Journal of Engineering for Gas Turbines and Power, vol. 123, 2001, pp. 741-746.

Doi: $10.1115 / 1.1383772$ 
[40] Gascoin, N., Gillard, P., Bernard, S., and Bouchez, M., "Characterization of coking activity during supercritical hydrocarbon pyrolysis," Fuel Processing Technology, vol. 89, 2008, pp. 1416-1428.

Doi: 10.1016/j.fuproc.2008.07.004

[41] Huang, Y., and Yang, V., "Effect of swirl on combustion dynamics in a lean-premixed swirl-stabilized combustor," Proceedings of the Combustion Institute, vol. 30, 2005, pp. $1775-1782$.

Doi: 10.1016/j.proci.2004.08.237

[42] Powell, O., Edwards, J. T., Norris, R. B., Numbers, K. E., and Pearce, J., "Development of Hydrocarbon-Fueled Scramjet Engines: The Hypersonic Technology Program," Journal of Propulsion and Power, vol. 17, 2001, pp. 1170-1176.

Doi: $10.2514 / 2.5891$

[43] Sicard, M., Raepsaet, B., Ser, F., and Masson, C., "Thermal decomposition of a model endothermic fuel. Preliminary study before testing in the MPP-LAERTE supersonic combustion test bench," 14th AIAA/AHI Space Planes and Hypersonic Systems and Technologies Conference, Canberra, Australia, November 6-10, 2006.

Doi: $10.2514 / 6.2006-7974$

[44] Wu, X., Yang, J., Zhang, H., and Shen, C., "System design and analysis of hydrocarbon scramjet with regeneration cooling and expansion cycle," Journal of Thermal Science, vol. 24, 2015, pp. 350-355.

Doi: 10.1007/s11630-015-0794-y

[45] Edwards, T., and Zabarnick, S., "Supercritical fuel deposition mechanisms," Industrial \& Engineering Chemistry Research., vol. 32, 1993, pp. 3117-3122.

Doi: $10.1021 / \mathrm{ie} 00024 \mathrm{a} 022$

[46] Gascoin, N., "High temperature and pressure reactive flows through porous media," International Journal of Multiphase Flow, vol. 37, 2011, pp. 24-35.

Doi: 10.1016/j.ijmultiphaseflow.2010.09.001

[47] Blevins, L. G., and Pitts, W. M., "Modelling of bare and aspirated thermocouples in compartment fires," Fire Safety Journal, vol. 33, issue 4, 1999, pp. 239-259.

Doi: 10.1016/S0379-7112(99)00034-X 
[48] Brohez, S., Delvosalle, C., and Marlair, G., "A two-thermocouples probe for radiation corrections of measured temperatures in compartment fires," Fire Safety Journal, vol. 39, 2004, pp. 399-411.

Doi: 10.1016/j.firesaf.2004.03.002

[49] Pitts W. M., Braun E., Peacock R. D., Mitler H. E., Johnsson E. L., Reneke P. A., and Blevins L. G,. "Temperature uncertainties for bare-bead and aspirated thermocouple measurements in fire environments," National Institute of Standards and Technology Internal Report NISTIR 6242, Annual Conference on Fire Research, November 2-5, 1998.

[50] Luo M., "Effects of radiation on temperature measurement in a fire environment," Journal of Fire Sciences, vol. 15, 1998, pp. 443-461.

Doi: $10.1177 / 073490419701500602$

[51] Carvalho J. A., Dos Santos W. F. N., "Radiation errors in temperature measurements with thermocouples in a cylindrical combustor", International Communications in Heat and Mass Transfer, vol. 17, 1990, pp. 663-673.

Doi: 10.1016/0735-1933(90)90014-B

[52] Roberts, I. L., Coney, J. E. R., and Gibbs, B. M., "Estimation of radiation losses from sheathed thermocouples," Applied Thermal Engineering, vol. 31, 2011, pp. 2262-2270.

Doi: 10.1016/j.applthermaleng.2011.03.020

[53] Goodwin, D. G., Moffat, H. K., and Speth, R. L., "Cantera: An object- oriented software toolkit for chemical kinetics, thermodynamics, and transport processes," http://www.cantera.org, 2016, Version 2.2.1.

[54] Dagaut, P., Boettner, J. C., and Cathonnet, M., "Ethylene pyrolysis and oxidation: A kinetic modeling study," International Journal of Chemical Kinetics, vol. 22, 1990, pp. $641-664$.

Doi: $10.1002 /$ kin. 550220608

[55] Frenkel, M., "Thermodynamics Source Database" in NIST Chemistry WebBook, http://webbook.nist.gov/chemistry/.

[56] Hottel, H. C., Noble J. J., Sarofim A. F., Silcox G. D., Wankat P. C., and Knaeble K. S., "Heat and Mass Transfer," Perry's Chemical Engineers' Handbook, edited by Perry, R. H., and Green, D. W, New York, McGrow-Hill, 2008, pp. 7-12. 
[57] Jarray, M., Chetehouna, K., Gascoin, N., and Bey, F., "Ceramic panel heating under impinging methane-air premixed flame jets," International Journal of Thermal Sciences, vol. 107, 2016, pp. 184-195.

Doi: 10.1016/j.ijthermalsci.2016.04.014

[58] Qin, J., Bao, W., Zhou, W. X., and Yu, D. R., "Flow and heat transfer characteristics in fuel cooling channels of a re-cooling cycle," International Journal of Hydrogen Energy, vol. 35, 2010, pp. 10589-10598.

Doi: 10.1016/j.ijhydene.2010.08.019

[59] Whitaker, S., "Forced Convection Heat Transfer Correlations for Flow in Pipes, Past Flat Plates, Single Cylinders, Singles Spheres, and for Flow in Packed Beds and Tube Bundles," AIChE Journal, vol. 18, 1972, pp. 361-371.

Doi: 10.1002/aic.690180219

[60] Gascoin, N., Gillard, P., Bernard, S., Abraham, G., Bouchez, M., and Daniau, E. T., "Measurements for fuel reforming for scramjet thermal management and combustion optimization: status of the COMPARER project," 14th AIAA/AHI Space Planes and Hypersonic Systems and Technologies Conference, Canberra, November 6-9, 2006.

Doi: $10.2514 / 6.2006-8005$

[61] Frey, F. E., and Smith, D. F., "Thermal Decomposition of Ethane, Ethylene, Propane, and Propylene," Industrial and Engineering Chemistry, vol. 20, 1927, pp. 948-951.

Doi: $10.1021 / \mathrm{ie} 50225 \mathrm{a} 022$

[62] Towell, G. D., and Martin, J. J., "Kinetic data from non-isothermal experiments: Thermal decomposition of ethane, ethylene, and acetylene," AIChE Journal, vol. 7, 1961, pp. 693698.

Doi: $10.1002 /$ aic. 690070432

[63] Tanzana, T., and Gardiner, W. C., "Thermal Decomposition of Ethylene", Combustion and Flame, vol. 39, issue 3, 1980, pp. 241-253.

Doi: 10.1016/0010-2180(80)90021-8

[64] Wu, K. K., Chang, Y. C., Chen, C. H., and Chen, Y. D., "High-efficiency combustion of natural gas with 21-30\% oxygen-enriched air," Fuel, vol. 89, 2010, pp. 2455-2462.

Doi: 10.1016/j.fuel.2010.02.002 
[65] Wersborg, B. L., Fox, L. K., and Howard, J. B., "Soot concentration and absorption coefficient in a low-pressure flame," Combustion and Flame, vol. 24, 1975, pp. 1-10.

Doi: 10.1016/0010-2180(75)90122-4

[66] De Ris, J., "FIRE RADIATION-A REVIEW,” 1960.

[67] Ciajolo, A., D’Anna, A., Barbella, R., Tregrossi, A., and Violi, A., "The effect of temperature on soot inception in premixed ethylene flames," Symposium (International) on Combustion, vol. 26, 1996, pp. 2327-2333.

Doi: 10.1016/S0082-0784(96)80061-0 


\section{List of Figures}

Fig. 1. Scheme of the regeneratively cooled combustion chamber.

Fig. 2. Scheme representing the position of the thermocouples measuring the combustion gases temperature.

Fig. 3. Sequence representing how thermocouples are moved during each test.

Fig. 4. Schemes showing the influence of $\dot{\mathrm{m} f}$ and $\varphi$ on combustion chamber dynamics.

Fig. 5. Variation of combustion gases temperatures with time for test 6 .

Fig. 6. Variation of $T_{h f}$ with time for test 6.

Fig. 7. Variation of $T_{h f}$ with time for test 6.

Fig. 8. Flame temperature profile along the axis at steady state for test 6 .

Fig. 9. Fuel residence time $t_{f}$ as a function of $\dot{m f}$ at steady state for test 6 .

Fig. 10. Variation of $d T_{h f} d t$ with time for test 6.

Fig. 11. Variation of $d P_{f} / d t$ with time for test 6.

Fig. 12. $T_{h f}$ at steady state for tests 2,3 , and 4 .

Fig. 13. Pictures of the flame for $\varphi=1.0$ (a), $\varphi=1.25$ (b), and $\varphi=1.5$ (c) Fig. 14. Combustion gases temperatures measured by thermocouples TC3, TC6 and TC11 for tests 2,3 , and 4 .

\section{List of Tables}

Tab. 1. Test cases for different operating conditions.

Tab. 2. Time events during the operation of test case number 6 .

Table 3. Comparison between system response time and fuel residence time in the cooling channel for test 6 .

Tab. 4. Times $d T_{h f} d t$ and $d P_{f} / d t$ need to reach $1 / 8$ of the maximum values after $\dot{m}_{f}$ variations.

Tab. 5. Average residence times at steady state for tests 2,3 , and 4 .

Tab. 6. Fuel heating rate variations following fuel flow rate variations for tests 2,3 , and 4 . 